\title{
A finite element performance-based approach to correlate movement of a rigid retaining wall with seismic earth pressure
}

DOI:

10.1016/j.soildyn.2018.07.025

\section{Document Version}

Accepted author manuscript

Link to publication record in Manchester Research Explorer

Citation for published version (APA):

Bakr, J., \& Ahmad, S. M. (2018). A finite element performance-based approach to correlate movement of a rigid retaining wall with seismic earth pressure. Soil Dynamics and Earthquake Engineering, 114, 460-479.

https://doi.org/10.1016/j.soildyn.2018.07.025

\section{Published in:}

Soil Dynamics and Earthquake Engineering

\section{Citing this paper}

Please note that where the full-text provided on Manchester Research Explorer is the Author Accepted Manuscript or Proof version this may differ from the final Published version. If citing, it is advised that you check and use the publisher's definitive version.

\section{General rights}

Copyright and moral rights for the publications made accessible in the Research Explorer are retained by the authors and/or other copyright owners and it is a condition of accessing publications that users recognise and abide by the legal requirements associated with these rights.

\section{Takedown policy}

If you believe that this document breaches copyright please refer to the University of Manchester's Takedown Procedures [http://man.ac.uk/04Y6Bo] or contact uml.scholarlycommunications@manchester.ac.uk providing relevant details, so we can investigate your claim.

\section{OPEN ACCESS}




\section{A finite element performance-based approach to correlate movement of a rigid retaining wall with seismic earth pressure}

Junied Bakr ${ }^{\mathrm{a}}$, Syed Mohd Ahmad ${ }^{\mathrm{b}, *}$

aPhD Student, School of Mechanical, Aerospace and Civil Engineering, The University of Manchester, Manchester, M13 9PL, United Kingdom. Email: junied.bakr@postgrad.manchester.ac.uk.

${ }^{b}$ Lecturer in Geotechnical Engineering, School of Mechanical, Aerospace and Civil Engineering, The University of Manchester, Manchester, M13 9PL, United Kingdom. Email: mohammed.ahmad.syed@manchester.ac.uk.

\section{* Corresponding author:}

Dr Syed Mohd Ahmad

Lecturer in Geotechnical Engineering

School of Mechanical, Aerospace and Civil Engineering

University of Manchester

Manchester

M13 9PL

Email: mohammed.ahmad.syed@manchester.ac.uk

Tel: $+44(0) 1613064637$ 


\section{ABSTRACT}

The paper presents a unique finite element model-based investigation and development of a relationship between the seismic active and passive earth pressure and the movement of a rigid retaining wall. A hardening soil with small strain model with consideration of the Rayleigh damping has been adopted for modelling soil. Validation of the finite element model has been carried out by using centrifuge test results already available in the literature. Unique design charts have been proposed highlighting the relationship between the seismic earth pressure and the wall movement. It is observed that the seismic active earth pressure is independent of the seismic input motion and hence does not depend upon the wall movement during an earthquake, while on the contrary the seismic passive earth pressure is significantly affected by it. Comparison of the results of the present study with the Mononobe-Okabe and pseudo-dynamic methods clearly highlights that the latter overestimates the seismic earth pressure. The proposed design charts and other results provide an important cue to the design engineers.

\section{Keywords:}

seismic earth pressure; relative horizontal displacement; retaining wall rotation; seismic inertia force; seismic input motion frequency content; soil-structure interaction 


\section{Introduction}

Retaining walls are one of the most important civil engineering structures constructed to provide lateral support to soil and are widely used in transportation systems, mines, underground structures, and military defences. In order to assess the stability of these structures, an accurate estimation of the lateral earth pressure is very important. Pioneering work on the estimation of lateral earth pressure was done by Coulomb and Rankine [1, 2]. From the classic literature on earth pressure, it is noted that the mode, direction, and magnitude of the retaining wall displacement have a significant effect on the development of active and passive lateral earth pressures. For example, through analytical work presented by [3-5] and experimental work presented by $[6,7]$, it is found that the magnitude of lateral earth pressure is highly influenced by the direction of the retaining wall movement while the mode of the retaining wall movement controls the distribution of lateral earth pressure along the height of the retaining wall. Numerical techniques like the finite element and finite difference methods have been used to provide an indepth understanding of the relationship between the lateral earth pressure and the displacement of retaining walls [8-11], and interesting findings have been made about the different modes and amount of the movement of the retaining wall on the magnitude and distribution of earth pressure. In the earthquake prone areas, an accurate estimation of the seismic earth pressure becomes pivotal for the design of such retaining walls. Okabe and Mononobe [12, 13] did a pioneering work to propose a method for the estimation of the seismic earth pressure by extending the Coulomb's static earth pressure theory. The method proposed by Okabe and Mononobe is very widely used in current practice and is often called as the Mononobe-Okabe or simply the MO method. In this method, the effect of the earthquake is simulated by introducing additional forces called as the seismic inertia forces on to a soil wedge which exert lateral earth pressure on the retaining wall, called as the seismic earth pressure. Over the past many years, many researchers like [14-20] have modified and extended the MO method to propose new analytical solutions like 
the pseudo-dynamic method to compute the seismic earth pressure while other researchers like [21-24] developed experimental and numerical methods to compute the seismic earth pressure by using the MO method. Further, $[25,26]$ have developed numerical methods for studying the phasing issues for the seismic response of yielding and non-yielding gravity retaining walls. However, it is important to highlight that the MO method does not take into account the displacement of the retaining wall under seismic conditions and hence, it is categorised as a forcebased method. Real field observations as reported by [21, 27] have shown that the retaining walls undergo large displacements during earthquakes. Richards and Elms [28] proposed an analytical solution by extending the Newmark sliding block method [29] to estimate the displacement of a retaining wall during an earthquake. Many researchers like [30-41] have also provided analytical, experimental, and numerical work based on the Newmark sliding block method and thereby applying the displacement-based approach to compute the displacement and rotation of a retaining wall under seismic loading; and as such assessing the stability of retaining structures based on allowable displacement.

Like for the static case, researchers over the years have tried to investigate the relationship between the retaining wall displacement and development of seismic earth pressure. For example, an elastic solution to study the influence of retaining wall flexibilities on seismic earth pressure was presented by [42] and the analysis showed that the maximum wall force was significantly smaller than that obtained by the conventional force-based method. Similarly, [43] proposed the intermediate wedge approach to consider the mobilization of frictional resistance for the development of the seismic earth pressure, while [43] presented a closed-form solution for the estimation of seismic earth pressure coefficient, which inherently was derived by considering the mode and level of the retaining wall movement, non-uniform seismic acceleration distribution with depth of the retaining wall, and phase effect. A simple kinematic method was proposed by [44] considering the soil-structure interaction effect and nonlinear behaviour of the backfill material. 1-g shaking table test was developed by [45] and observations showed that the seismic 
earth pressure was significantly affected by the displacement of the retaining wall. [46] carried out a numerical study to investigate the seismic earth pressure on flexible retaining walls, and found that the increase of wall flexibility leads to reduce the seismic earth pressure. [47] presented a comparison between the analytical and experimental results, and highlighted the importance of wall flexibility on the seismic earth pressure. Further, centrifuge test results presented by [48] and [21] show that the force-based methods do not reflect the real behaviour of a retaining wall during an earthquake and the computed seismic earth pressures are unrealistic. From the above discussion, it is clear that despite the obvious dependence of the seismic earth pressure on the retaining wall movement, this area lacks an in-depth understanding. Specifically, no consideration has been given to understand:

1. The relationship between the seismic earth pressure and the displacement of retaining wall by simultaneously considering the development of active and passive states during an earthquake;

2. The interaction between the retaining wall and backfill and as well as the foundation soil material by considering the deformation mechanism (i.e., the sliding and rotational displacement) of the retaining wall-soil system;

3. The procedure required to estimate the relative displacement between the retaining wall and foundation soil during an earthquake;

4. The effects of the amplification and de-amplification of seismic input motion on the development of both the seismic active and passive earth pressure and as well as on the relative sliding displacement of the retaining wall;

5. The relative contribution of the seismic earth pressure force to the total driving force which causes the sliding of a retaining wall relative to the foundation soil during an earthquake;

6. The influence of the amplitude and frequency content of the seismic input motion on the development of seismic active and passive earth pressure and as well as on the sliding displacement of the retaining wall; and 
7. The effect of the foundation soil deformability.

In the present paper, an attempt has thus been made to address the above issues. For this purpose, a simple yet versatile finite element (FE) model has been developed using the commercial geotechnical software PLAXIS2D [49], with an aim to provide an in-depth analysis of the seismic performance of a rigid retaining wall under seismic loading. The first part of this paper includes the development of a FE model and its validation using centrifuge test results of Saito et al. (as reported in [50]) and Nakamura [48], already available in literature; while the latter part of the paper presents an in-depth investigation of the development of the seismic earth pressure, both for the active and passive cases and its dependency on the retaining wall movement. Unique design charts highlighting this relationship are proposed and also critical comparisons have been made with the conventional MO and pseudo-dynamic methods.

\section{Problem definition}

A typical rigid retaining wall of height $H$, retaining dry cohesionless backfill soil to its full height and seated on a dry foundation of thickness $h$, is shown in Fig. 1. Under the static and seismic conditions, the retaining wall will be subject to static and seismic earth pressure, respectively. For the seismic earth pressure case, the retaining wall will undergo lateral movement in the horizontal direction (along the $x$-axis) and/or rotation (in the $x$-y plane-see Fig. 1). Depending upon the direction in which the retaining wall moves and/or rotates the soil behind the retaining wall will either be in an active state or passive state of earth pressure. As discussed above, the objective of this paper is to study the effect of the wall movement and/or rotation on the development of the seismic earth pressure. For this purpose, a FE model of the rigid retaining wall as depicted in Fig. 1 has been constructed and the same has been analysed for the seismic case. 


\section{Finite element model}

PLAXIS2D [49] has been used to develop the FE model of the retaining wall and is shown in Fig. 2. The model consists of a $4 \mathrm{~m}$ high trapezoidal cross-section retaining wall with a top width of $1.5 \mathrm{~m}$ and base width of $3 \mathrm{~m}$. The retaining wall is resting on a $10 \mathrm{~m}$ thick foundation soil. The retaining wall retains a dry cohesionless soil to its full height. It is assumed that a $2 \mathrm{D}$ plane-strain condition exists by considering that the length of the retaining wall is significantly large in comparison to the extents in the $x$ - and $y$-directions. To ensure that the boundary effects are minimized from the analysis, a large domain extending $25 \mathrm{~m}$ to the right and $20 \mathrm{~m}$ to the left of the back-face of the retaining wall has been considered.

\subsection{Finite element mesh}

The soil both in the backfill and foundation and the retaining wall has been modelled by using 6-noded triangular elements of the PLAXIS2D library [49], and are shown in Fig. 2. As per the findings of [51], it is important to note that as the retaining wall is to be modelled for the seismic case, which will involve propagation of the shear waves through the backfill and foundation soil, the maximum size of any element should not be greater than $20 \%$ of the wavelength of a shear wave propagating through the soil. This means, that if $\lambda_{\min }$ and $v_{\mathrm{s}}$ is the wavelength and velocity of the shear wave, respectively, and $f_{\max }$ is the maximum frequency of the seismic input motion, then the maximum height of an element of the FE mesh $h \mathrm{e}_{\max }$ should be:

$$
h \mathrm{e}_{\max }=\frac{\lambda_{\min }}{5}=\frac{v_{\mathrm{s}}}{5 f_{\max }}
$$

Eq. (1) is already satisfied by the mesh generation procedure adopted by PLAXIS2D [49]. The retaining wall, backfill and foundation soil are discretized in 40, 352, and 1014 elements, respectively (Fig. 2). The number of elements has been decided after carrying out a convergence analysis as shown in the Appendix 1. 


\subsection{Constitutive model for the backfill and foundation soils}

To accurately simulate the behaviour of the backfill and foundation soil under seismic conditions, it is crucial that the chosen constitutive model considers the following: stressdependency of the soil stiffness, loading and unloading cycles, nonlinear shear modulus reduction with shear strain, and generation of hysteretic damping during seismic loading. In this study, a hardening soil with small strain model (referred from here on in this paper as 'HSsmall model') has been selected as the constitutive model for the soil. The salient features of the HSsmall model are noted below:

- It is an elastoplastic constitutive model;

- The stiffness of the soil is simulated by considering $E_{50}$, which, in PLAXIS2D [49] is defined as the modulus of soil at $50 \%$ of the soil's strength at failure $q_{\mathrm{f}}$ (as depicted in Fig. 3). Mathematically, $E_{50}$ is related to the effective confining pressure $\sigma_{3}^{\prime}$ by:

$$
E_{50}=E_{50}^{\mathrm{ref}}\left(\frac{c^{\prime} \cos \phi^{\prime}-\sigma_{3}^{\prime} \sin \phi^{\prime}}{c^{\prime} \cos \phi^{\prime}+p^{\mathrm{ref}} \sin \phi^{\prime}}\right)^{\mathrm{y}}
$$

where $E_{50}^{\mathrm{ref}}=$ modulus of soil at $50 \%$ of the soil's strength at failure, corresponding to a reference confining pressure $p^{\mathrm{ref}}\left(=100 \mathrm{kN} / \mathrm{m}^{2}-\right.$ as noted in PLAXIS2D [49]), $c^{\prime}=$ effective cohesion of the soil, $\phi^{\prime}=$ effective friction angle of the soil, $y=$ a constant, to account for the stress-level dependency of the stiffness of the soil. For PLAXIS2D [49], the value of $y$ is considered to be between $0.5-1$. From Fig. 3, it is observed that the soil's strength at failure $q_{\mathrm{f}}$ is marginally smaller than the asymptotic value to the soil's strength at failure $q_{\mathrm{a}}$. The ratio $q_{\mathrm{f}} / q_{\mathrm{a}}$ is called as the failure ratio $R_{\mathrm{f}}$, and in PLAXIS2D [49] it is usually taken as 0.9 . It is considered that for $R_{\mathrm{f}}=1$, the failure criterion is reached and perfectly plastic yielding occurs as described by the MohrCoulomb failure criterion. 
- To simulate the stress history of the soil, modulus of soil obtained from an oedometer test $E_{\text {oed }}$ is used, which is computed by [49]:

$$
E_{\text {oed }}=E_{\text {oed }}^{\mathrm{ref}}\left(\frac{c^{\prime} \cos \phi^{\prime}-\sigma_{3}^{\prime} \sin \phi^{\prime}}{c^{\prime} \cos \phi^{\prime}+p^{\mathrm{ref}} \sin \phi^{\prime}}\right)^{\mathrm{y}}
$$

where $E_{\text {oed }}^{\text {ref }}=$ modulus of the soil obtained from an oedometer test, corresponding to a reference confining pressure $p^{\text {ref }}$. In PLAXIS2D [49], $E_{\text {oed }}^{\text {ref }}=E_{50}^{\text {ref }}$

- The unloading and reloading is simulated by using the modulus of the soil for unloadingreloading conditions $E_{\mathrm{ur}}$, which is determined by:

$E_{\mathrm{ur}}=E_{\mathrm{ur}}^{\mathrm{ref}}\left(\frac{c^{\prime} \cos \phi^{\prime}-\sigma_{3}^{\prime} \sin \phi^{\prime}}{c^{\prime} \cos \phi^{\prime}+p^{\mathrm{ref}} \sin \phi^{\prime}}\right)^{\mathrm{y}}$

where $E_{\mathrm{ur}}^{\mathrm{ref}}=$ modulus of the soil for unloading-reloading conditions, corresponding to a reference confining pressure $p^{\text {ref }}$ (see Fig. 3).

- For estimating the shear modulus of the soil for the unloading and reloading conditions $G_{\mathrm{ur}}$, the Hardin and Drnevich relationship [52], given by Eq. 5, is used:

$G_{\mathrm{ur}}=\frac{G_{\mathrm{o}}}{1+\left|\frac{\gamma}{\gamma_{0.7}}\right|}$

where $G_{0}=$ initial small strain shear modulus of the soil $\left(\gamma<10^{-6}\right), \gamma=$ shear strain, $\gamma_{0.7}=$ reference shear strain, corresponding to $70 \%$ of $G_{0}$. The above reduction of the shear modulus, as shown in Fig. 4(a) also simulates the hysteretic damping as discussed below and shown in Fig. 4(b).

During the earthquake loading, because of the internal friction of soil particles, a certain amount of energy is dissipated. Such dissipated internal energy is referred to as the hysteretic damping and this needs to be considered in the FE formulation. However, as the chosen HSsmall 
model is (almost) linear at very small strain with no hysteretic damping (see Fig. 4(a)), a viscous damping, which is frequency dependent, is used in the present study [38]. The viscous damping has been considered by using the Rayleigh damping formulation and is given by:

$[\boldsymbol{C}]=\alpha[\boldsymbol{M}]+\beta[\boldsymbol{K}]$

where $[\boldsymbol{C}],[\boldsymbol{M}]$ and $[\boldsymbol{K}]=$ damping, mass and stiffness matrices of the system, respectively, $\alpha$ and $\beta=$ Rayleigh parameters, which are computed by Eq. 7, [38]

$\left\{\begin{array}{l}\alpha \\ \beta\end{array}\right\}=\frac{2 \xi}{\omega_{\mathrm{z} 1}+\omega_{\mathrm{z} 2}}\left\{\begin{array}{c}\omega_{\mathrm{z} 1} \times \omega_{\mathrm{z} 2} \\ 1\end{array}\right\}$

where $\xi=$ damping ratio, $\omega_{\mathrm{z} 1}$ and $\omega_{\mathrm{z} 2}=$ first two natural circular frequencies of the FE model. It is to be noted that the Rayleigh parameters are used in the study to produce the FE damping matrix, which is proportional to the mass and stiffness matrices as shown in Eq. 6. It can be noted from Eq. 7 that $\alpha$ and $\beta$ vary with the viscous damping ratio and natural circular frequencies of the FE model. In the FE simulation, the values of the Rayleigh parameters $\alpha$ and $\beta$ are computed for a critical viscous damping ratio (say $3 \%$ or $5 \%$ ) for which the frequency of the system will be between the first two natural circular frequencies $\omega_{z 1}$ and $\omega_{z 2}$. It is important to note that the Rayleigh damping formulation is based on the first two modes of the natural frequency of the soilretaining wall system because the response of the retaining walls is usually governed by their first two modes of vibrations [23]. [23] reported that over $97 \%$ of the total displacement of a retaining wall is captured in the first and second modes of vibration, while only about $3 \%$ of the total displacement comes from the third mode of vibration. ABAQUS [54] has been used to determine the natural circular frequencies of the first two modes of vibration for the soil-retaining wall system. 


\subsection{Constitutive model for the retaining wall}

The rigid retaining wall as shown in Fig. 2 is modelled by using a linear viscoelastic constitutive model. A similar consideration was made by other researchers in the past like [38, 39]. Viscous damping is used for the retaining wall as well, which, like soil, was simulated by using the Rayleigh damping formulation.

\subsection{Soil-retaining wall interaction}

The interaction between the soil and the retaining wall is modelled by using the 6-noded interface elements as shown in the inset of Fig. 2.

\subsection{Boundary conditions and initial static analysis}

As shown in Fig. 2, the lateral boundaries are considered to be restrained against horizontal displacement while the base boundary is restrained against the horizontal and vertical displacements. With these boundary conditions, an initial static analysis is carried out by applying the gravity loading for the soil-retaining wall system so as to define the initial stress state.

\subsection{Seismic loading}

The effect of the earthquake on the soil-retaining wall system is simulated by applying a horizontal acceleration-time history at the base of the FE model as shown in Fig. 2. This acceleration-time history may be defined by using a real earthquake-time history or an equivalent sinusoidal acceleration-time history. For this study, a real earthquake-time history of the Loma Prieta (1989) earthquake (as shown in Fig. 5) and as well as an equivalent sinusoidal earthquaketime history have been used. 


\subsection{Absorbing boundaries for the seismic analysis}

The demarcation of the boundaries of a FE model for carrying out a seismic analysis is very different from the static analysis. This is because, in the seismic analysis, the shear waves are reflected back into the soil from the boundaries of the domain under consideration, thereby making the results not 'free-from-boundary-effects'. To counter the problem of the waves getting reflected back into the soil, absorbing boundaries are used in this study. This is a widely used and accepted technique as is reported in $[21,38]$.

\section{Validation of the proposed finite element model}

It is important to validate the proposed FE model so that its reliability can be ascertained before detailed results are obtained from it. In general, a validation of a numerical study is often carried out by either using analytical models or experimental results. As proposing an analytical model or carrying out an experimental work was beyond the scope of the present study, results from two centrifuge tests available in literature have been chosen to validate the proposed FE model. These centrifuge tests were carried out by Saito et al. (see [50]) and Nakamura [48] to study the seismic behaviour of a rigid retaining wall, and had the following features:

- A model of a rigid retaining wall, $30 \mathrm{~cm}$ high and seated on a $10 \mathrm{~cm}$ thick foundation soil was tested in a centrifuge (Fig. 6).

- Dry Toyoura sand was used as the backfill and foundation soil at a relative density $\left(D_{\mathrm{r}}\right)$ of $82 \%$ for the centrifuge test conducted by Saito et al. (see [50]), and $88 \%$ for the centrifuge test conducted by Nakamura [48].

- To observe the horizontal displacement of the base of the retaining wall for the Saito et al. centrifuge test (see [50]), the seismic loading was simulated by applying an equivalent 
sinusoidal acceleration-time history at the base of the model with an acceleration of $0.4 \mathrm{~g}$ and a frequency of $1.5 \mathrm{~Hz}$ for $25 \mathrm{~s} \mathrm{(Fig.} \mathrm{7(a)).}$

- However, for the Nakamura [48] centrifuge test, three sinusoidal acceleration-time histories were applied at the base of the model:

- The first sinusoidal acceleration-time history was increased by 17 gal per wave with a frequency of $2 \mathrm{~Hz}$ for $21 \mathrm{~s}$ as shown in Fig. 7(b) to observe the horizontal displacement at the top of the retaining wall.

- The second uniform sinusoidal acceleration-time history was used with a uniform acceleration of $600 \mathrm{gal}$ and a frequency of $2 \mathrm{~Hz}$ for $16 \mathrm{~s}$ as shown in Fig. 7(c) to observe the variation of the seismic earth pressure with the height of the retaining wall.

- The third uniform sinusoidal acceleration-time history was applied with an acceleration of $600 \mathrm{gal}$ and a frequency of $4 \mathrm{~Hz}$ for $9 \mathrm{~s}$ as shown in Fig. 7(d) to observe the increment of the seismic earth pressure force-time history.

FE models for the abovementioned centrifuge models is developed in PLAXIS2D [49] - the FE mesh for these tests is shown in Fig. 8(a), (b). The soil and retaining wall properties and other parameters required to run the PLAXIS2D [49] simulation for these FE models are shown in Table 1. ABAQUS [54] is used to obtain the Rayleigh parameters $\alpha$ and $\beta$. Fig. 9 shows the horizontal displacement at the base and top of the retaining wall obtained from the FE model and its comparison with the centrifuge test results of Saito et al. (see [50]) and Nakamura [48]. Fig. 10 shows the variation of the seismic earth pressure with the height of the retaining wall for the active and passive cases computed by the FE model and its comparison with the centrifuge test result of Nakamura [48], while Fig. 11 shows the increment of seismic earth pressure force-time history predicted by the centrifuge test result of Nakamura [48] and its comparison with the FE model. From these results and comparison, it is observed that the results from the FE model match very well with the centrifuge test results qualitatively. The slight quantitative mismatch between the results may be attributed to the inability of the chosen soil constitutive model in replicating some 
complex aspects of the soil behaviour (e.g., soil softening and interaction between the soil and retaining wall under seismic loading).

\section{Results and discussion}

For the above FE model, predictions are made for the displacement of the retaining wall under seismic loading, with an aim to correlate the wall displacement with the seismic earth pressure. The soil and retaining wall properties and other parameters required to run the PLAXIS2D [49] simulation for the proposed FE were already measured and derived experimentally in the literature [55], and shown in Table 2. Through the FE model, the following outputs are obtained: acceleration response of the soil-retaining wall system, horizontal displacement and/or rotation of the retaining wall, horizontal seismic inertia force of the retaining wall and the seismic earth pressure force. It is important to highlight that the acceleration, horizontal displacement and/or rotation and the horizontal seismic inertia force of the retaining wall can have positive and negative senses, as shown in Fig. 12. A positive horizontal displacement and/or rotation means that the retaining wall moves towards the backfill soil, while a negative displacement and/or rotation means that the retaining wall moves away from the backfill soil. Likewise, a positive horizontal seismic inertia force of the retaining wall will act towards the backfill soil, while a negative horizontal seismic inertia force of the retaining wall act away from the backfill soil.

\subsection{Acceleration response of the soil-retaining wall system}

For the Loma Prieta (1989) seismic input motion (Fig. 5), the acceleration response of the soilretaining wall system is predicted for the following four locations of the FE model as shown in Fig. 1:

The centre of gravity of the retaining wall (CG); 
The base of the FE model $\left(b_{\mathrm{m}}\right)$;

The top of the retaining wall $\left(t_{\mathrm{w}}\right)$; and

The top of the backfill soil $\left(t_{\mathrm{b}}\right)$.

Fig. 13 shows the acceleration-time history predictions for the abovementioned locations for a duration between 3-8 s. The time window of $3-8 \mathrm{~s}$ has been chosen because during this time the earthquake intensity had the maximum concentration (as shown in Fig. 5). It is observed from Fig. 13 that for any particular time, the acceleration response for the top of the backfill (location $t_{\mathrm{b}}$ ) is lagging behind the acceleration response for the top of the retaining wall (location $t_{\mathrm{w}}$ ). Moreover, the acceleration response for both locations $t_{\mathrm{b}}$ and $t_{\mathrm{w}}$ is lagging behind the acceleration predicted at the base of the FE model (location $b_{\mathrm{m}}$; it is to be noted that seismic input motion is being applied at location $b_{\mathrm{m}}$ ). This implies that there is a phase difference in the acceleration response between locations $t_{\mathrm{b}}, t_{\mathrm{w}}$ and $b_{\mathrm{m}}$. Another important observation from the acceleration response is that the acceleration for the top of the retaining wall and top of the backfill (locations $t_{\mathrm{b}}$ and $t_{\mathrm{w}}$ ) is more than the acceleration predicted at the base of the FE model (location $b_{\mathrm{m}}$ ). As an illustration, at time $t=4.5 \mathrm{~s}$, the maximum acceleration at the top of the backfill (location $t_{\mathrm{b}}$ ) is about $0.67 \mathrm{~g}$, while the maximum acceleration at the base of the $\mathrm{FE}$ model (location $b_{\mathrm{m}}$ ) is only about $0.25 g$, which is approximately $40 \%$ less than the acceleration at the top of the FE model (locations $t_{\mathrm{b}}$ and $t_{\mathrm{w}}$ ). This highlights that the acceleration is being amplified towards the top of the FE model.

\subsection{Horizontal displacement and rotation of the retaining wall}

Fig. 14 shows the horizontal displacement predictions for the locations $C G, t_{\mathrm{w}}, t_{\mathrm{b}}$ and as well as at a point $0.5 \mathrm{~m}$ in the foundation soil below the base of the retaining wall (location $b_{\mathrm{f}}$ ). Figs. 15(a) and (b) show the relative horizontal displacement between locations CG and $b_{\mathrm{f}}$, and between locations $t_{\mathrm{w}}$ and $t_{\mathrm{b}}$, respectively. The relative horizontal displacement between locations CG and $b_{\mathrm{f}}$ 
represents sliding of the retaining wall. Fig. 16 shows the rotation of the retaining wall, which is computed by:

$\theta=\tan ^{-1}\left(\frac{\Delta t_{\mathrm{w}}-\Delta b_{\mathrm{w}}}{H}\right)$

where $\theta=$ rotation of the retaining wall about an axis passing through location $b_{\mathrm{w}}($ Fig. 1$), \Delta t_{\mathrm{w}}=$ horizontal displacement at the top of the retaining wall, $\Delta b_{\mathrm{w}}=$ horizontal displacement at the base of the retaining wall.

Figs. 14 and 15 are to be read in conjunction with the seismic input motion (Fig. 5). From Fig. 14(a) it is observed that the retaining wall initially moves towards the backfill soil, thereby creating a seismic passive earth pressure condition for the backfill soil. After about time $t=3.3 \mathrm{~s}$, the retaining wall starts to move away from the backfill soil; and in the process the retaining wall first comes back to its original (at-rest) position, and then starts to move away from the backfill soil until it attains a maximum horizontal displacement in the active direction at about time $t=3.8$ s (see point $d_{\text {active }}$ in Fig. 14(a)). The maximum displacement in the active direction almost corresponds to the maximum (positive) amplitude of the seismic input motion at time $t=3.8 \mathrm{~s}$ (see Fig. 5). As shown in Fig. 5, for time $t>3.8 \mathrm{~s}$, the seismic input motion again changes direction, thereby correspondingly forcing the retaining wall to move towards the backfill soil. The retaining wall continues to push towards the backfill soil until it has been displaced by a maximum amount (see point $d_{\text {passive }}$ in Fig. 14(a)), which, like for the active case, corresponds to the maximum amplitude of the seismic input motion at about time $t=4.5 \mathrm{~s}$. After time $t=4.5 \mathrm{~s}$, the retaining wall keeps on moving towards and away from the backfill soil, until about time $t=30 \mathrm{~s}-\mathrm{a}$ time at which the seismic input motion almost diminishes to 0 (Fig. 5). Figs. 14(b), (c) and (d) show that the horizontal displacement predicted for the locations $t_{\mathrm{w}}, t_{\mathrm{f}}$ and $b_{\mathrm{f}}$ are all following the trend of the horizontal displacement predicted at the centre of gravity of the retaining wall (location CG). 
For rotation of the retaining wall, a similar trend is observed: i.e., the retaining wall gets rotated by a maximum amount when the seismic input motion is acting towards the backfill soil (Fig. 16).

\subsection{Horizontal seismic inertia force of the retaining wall $F$}

The horizontal seismic inertia force of the retaining wall $F$ for a particular time is proportional to the acceleration and the negative value of the mass of the retaining wall and is computed by:

$$
F=-m \times a_{\mathrm{CG}}
$$

where $m=$ mass of the retaining wall and $a_{\mathrm{CG}}=$ acceleration at the centre of gravity of the retaining wall (location CG). As the acceleration is varying with depth (it is maximum at the top of the retaining wall and reduces towards the base), the acceleration at the centre of gravity of the retaining wall (location $\mathrm{CG}$ ) is determining by considering an average acceleration value. Fig. 17 shows the horizontal inertia force of the retaining wall, determined at its centre of gravity. The maximum horizontal seismic inertia force of the retaining wall $\left(F_{\mathrm{a}}\right)$ is about $75 \mathrm{kN} / \mathrm{m}$ acting away from the backfill soil, while the same $\left(F_{\mathrm{p}}\right)$ is about $121 \mathrm{kN} / \mathrm{m}$ acting towards the backfill soil.

\subsection{Seismic earth pressure force $P$}

The seismic earth pressure force $P$ has been estimated by the following procedure:

First, the horizontal stresses $\sigma_{\mathrm{ha}}$ and $\sigma_{\mathrm{hb}}$ are computed at those Gauss integration points, which are in contact with the retaining wall (points $a$ and $b$ in Fig. 2). These horizontal stresses are then averaged for each element, by using Eq. 10 as shown below:

$$
\sigma_{\text {hei }}=\frac{\sigma_{\text {ha }}+\sigma_{\mathrm{hb}}}{2}
$$

where $\sigma_{\text {hei }}=$ horizontal stress for each element. 
For each element, the seismic earth pressure force for the element $P_{\text {ei }}$ is computed by multiplying $\sigma_{\text {hei }}$ with the height of the element $h_{\mathrm{ei}}$ as shown by Eq. 11 below:

$$
P_{\mathrm{ei}}=\sigma_{\text {hei }} \times h_{\mathrm{ei}}
$$

The seismic earth pressure force $P$ will be:

$$
P=\sum_{\mathrm{i}=1}^{\mathrm{n}} P_{\mathrm{ei}}
$$

where $n=$ number of elements of the backfill soil which are in contact with the back of the retaining wall.

Fig. 18(a) shows the variation of the seismic earth pressure force $P$ with time $t$, while Fig. 18(b) is a simplified version of the seismic earth pressure force $P$ variation with time $t$ and has been obtained from Fig. 18(a). For Fig. 18(b) it is important to highlight that the static at-rest earth pressure force $P_{\mathrm{o}}$ for $t<0 \mathrm{~s}$ has been estimated using the $K_{\mathrm{o}}$-condition (where $K_{\mathrm{o}}$ is the at-rest earth pressure coefficient), while the static active earth pressure force $P_{\mathrm{a}}$ for $t=0 \mathrm{~s}$ has been predicted from the FE model at the beginning of the seismic analysis. For time $t>0 \mathrm{~s}$, seismic earth pressure force time history has been predicted directly from the seismic analysis for the duration of the seismic input motion. It is observed that during the static analysis (i.e., $t<0 \mathrm{~s}$ ), the retaining wall moves away from the backfill soil from its at-rest position to a partially active position. The at-rest earth pressure force condition is about $64.8 \mathrm{kN} / \mathrm{m}$, which gradually reduces to a value of about $45.85 \mathrm{kN} / \mathrm{m}$ (Fig. 17(b)). With the start of the seismic analysis (i.e., at $t=0 \mathrm{~s}$ ), the static earth pressure force of $45.85 \mathrm{kN} / \mathrm{m}$ further reduces until it attains a minimum value of about $42.36 \mathrm{kN} / \mathrm{m}$ (at $t=3.8 \mathrm{~s}$ approximately). From Fig. 14(a), it is clear that at time $t=3.8 \mathrm{~s}$, the retaining wall moved away from the backfill soil, thereby creating a state of seismic active earth pressure behind the retaining wall. Thus, it can be said that the seismic earth pressure force value of $42.36 \mathrm{kN} / \mathrm{m}$ at $t=3.8 \mathrm{~s}$ is actually the seismic active earth pressure force (Fig. 18(b)), $P_{\text {ae. }}$ Hence, mathematically, one can write the following: 
$P_{\mathrm{ae}}=P_{\mathrm{o}}-\Delta P_{\mathrm{ae}}$

where $\Delta P_{\mathrm{ae}}=$ seismic active earth pressure force increment. It is interesting to note that the static active earth pressure force $P_{\mathrm{a}}$ is also about $45.85 \mathrm{kN} / \mathrm{m}$, hence, one can say that:

$P_{\mathrm{ae}} \approx P_{\mathrm{a}}$

Eq. 14 suggests that for the active earth pressure case, the seismic earth pressure force $P_{\mathrm{ae}}$ is either close to or less than the static active earth pressure force $P_{\mathrm{a}}$. In other words, it can be said that there is no contribution of the horizontal seismic inertia forces of the backfill soil on the seismic active earth pressure force $P_{\text {ae }}$. This observation is in contrast with the conventional MO theory and pseudo-dynamic method, according to which:

$P_{\mathrm{ae}}=P_{\mathrm{a}}+\Delta P_{\mathrm{ae}}$

The above observation was also found to be valid in previous centrifuge modelling studies like [21] and [48].

With continued acceleration and at time $t=4.5 \mathrm{~s}$, the retaining wall starts to move towards the backfill soil (Fig. 14(a)), thereby developing a state of passive earth pressure behind the retaining wall and in the process gradually incrementing the earth pressure until it attains a maximum value of about $103.6 \mathrm{kN} / \mathrm{m}$ (Fig. 17(b)). The seismic earth pressure force increment $\Delta P$ is approximately equal to $103.6-42.36=61.24 \mathrm{kN} / \mathrm{m}$. It is interesting to note from Fig. $18(\mathrm{~b})$ that the seismic earth pressure force increment $\Delta P$ is given by:

$\Delta P=\Delta P_{\mathrm{ae}}+\Delta P_{\mathrm{pe}}$

where $\Delta P_{\mathrm{pe}}=$ seismic passive earth pressure force increment. Eq. 16 suggests that $\Delta P_{\mathrm{ae}}$ is contributing to bring the retaining wall back to the original at-rest condition, while $\Delta P_{\text {pe }}$ pushes the wall further towards the backfill soil, thereby creating a passive condition. Thus, as shown in Fig. 18(b), the following can be written: 
$P_{\mathrm{pe}}=P_{\mathrm{o}}+\Delta P_{\mathrm{pe}}$

Like the active case, the above observation was also found to be valid in previous centrifuge modelling studies like [21] and [48]. The above results are extremely important as they reveal very interesting facts about the MO and pseudo-dynamic methods. Fig. 19 shows the variation of the static and seismic earth pressure with the normalized height of the retaining wall $(z / H)$, where $z$ is the height of the wall measured above its base. As shown in Fig. 19(a), the static earth pressure from the FE model is very close to the static earth pressure estimated by using the Coulomb's earth pressure theory. Also, the distribution of the static earth pressure from the FE model is observed to be nonlinear, especially in the lower quarter of the height of the retaining wall. Fig. 19(b) shows the variation of the seismic active earth pressure with the normalized height of the retaining wall $(z / H)$. It is observed that the seismic active earth pressure $p_{a e}$ is very close to the Coulomb's active earth pressure, and clearly, it is significantly less than the earth pressure obtained by using the MO theory and pseudo-dynamic methods. Further, the variation of the seismic active earth pressure with the normalised height of the retaining wall $(z / H)$ is similar to the variation of static active earth pressure obtained using the FE model (Fig. 19(a)). This validates the findings of Eq. 15 and emphasises that the MO theory and pseudo-dynamic method significantly overestimate the seismic active earth pressure. Similarly, the distribution of the passive earth pressure with a normalised height of the retaining wall $(z / H)$ is nonlinear as shown in Fig. 19(c). It can also be noted that the seismic passive earth pressure is much higher than the atrest earth pressure and this validates the findings of Eq. 17. Fig. 19(d) shows the variation of the seismic earth pressure with the normalised height of the retaining wall $(z / H)$ at the end of the earthquake. It can be noted that the distribution of earth pressure is also nonlinear and it is similar to what was observed for the passive case (Fig. 19(c)). However, it is to be noted that the variation of the seismic earth pressure with the pseudo-dynamic method is linear, implying that the backfill moves in phase - this is in contrast to the findings of [15], who obtained non-linear seismic earth pressure distributions. This apparent disparity is only because the frequency content 
of the seismic input motion used in the current FE analysis is very low $(0.7 \mathrm{~Hz})$, while [19] use a frequency content of $3 \mathrm{~Hz}$ or larger.

5.5. Effect of the horizontal seismic inertia force of the retaining wall $F$ on seismic earth pressure force increment $\Delta P$

Fig. 20 shows a relationship between the horizontal seismic inertia force of the retaining wall $F$ and seismic earth pressure force increment $\Delta P$. It is observed that when the maximum horizontal seismic inertia force of the retaining wall $F$ acts in the active direction at time $t=3.8 \mathrm{~s}$, the seismic earth pressure force increment $\Delta P$ is almost equal to 0 . It is also observed that the maximum seismic earth pressure force increment $\Delta P$ occurs at time $t=4.5 \mathrm{~s}$ when the horizontal seismic inertia force of the retaining wall $F$ acts in the passive direction. This means that there is a phase difference between the horizontal seismic inertia force of the retaining wall $F$ and seismic earth pressure force increment $\Delta P$. This observation matches very well with what has been discussed in [25]. Thus, it can be said that for the active case it is the horizontal seismic inertia force of the retaining wall $F$ along with the static active earth pressure force $P_{\mathrm{a}}$ which are controlling the displacement and/or the rotation of retaining wall. In other words, the seismic earth pressure force increment $\Delta P$ does not contribute to the displacement and/or rotation of the retaining wall. This observation matches very well with what has been discussed in Section 5.4 above and consequently what has been proved by Eq. 14. On the other hand, for the seismic passive earth pressure case, the displacement and/or rotation of the retaining wall is affected by both the horizontal seismic inertia force of the retaining wall $F$ and the seismic earth pressure force increment $\Delta P$. Like the active case, this observation matches well with what has been mentioned in Section 5.4 and consequently proved by Eq. 17. 


\subsection{Effect of the wall displacement on horizontal seismic inertia force of the retaining wall $F$}

On comparing Fig. 17 with Fig. 14(a), it is observed that the horizontal displacement of the retaining wall follows the trend of the horizontal seismic inertia force of the retaining wall $F$. Similarly, it is also observed that the retaining wall experiences maximum displacement away from the backfill when the maximum horizontal seismic inertia force of the retaining wall $F$ acts in the same direction as the direction of the retaining wall displacement.

\subsection{Effect of the wall displacement on seismic earth pressure force $P$}

Studying Figs. 14, 15 and 16 in conjunction with Fig. 18 helps us to decipher a relationship between the horizontal displacement and/or rotation of the retaining wall and the seismic earth pressure force $P$. It is observed from Fig. 14(b) and (c) that the retaining wall and backfill soil move by a maximum amount in the active direction at time $t=3.8 \mathrm{~s}$ (point $\mathrm{d}_{\text {active }}$ in Fig. 14 (b) and (c)), while at time $t=4.5 \mathrm{~s}$ the retaining wall and backfill soil move by a maximum amount in the passive direction (point $d_{\text {passive }}$ in Figs. 14(b) and 14(c)). However, from Fig. 15(b), it can be noted that the relative displacement between the retaining wall and backfill soil has a maximum value at time $t=3.8 \mathrm{~s}$ in the active direction, thereby implying that the retaining wall is undergoing a larger displacement in the active direction than the backfill soil up to time $t=3.8 \mathrm{~s}$. As the retaining wall gets displaced more than the backfill soil, a state of seismic active earth pressure is developed inside the backfill soil. The same is shown in Fig. 18(a) at time $t=3.8 \mathrm{~s}$. Also, from Fig. 15(b) it can be observed that the relative displacement between the retaining wall and backfill soil has a maximum value at time $t=4.5 \mathrm{~s}$ in the passive direction, thereby implying that the retaining wall is undergoing a larger displacement in the passive direction than the backfill soil up to time $t=4.5$

s. Further, as the retaining wall gets displaced more than the backfill soil towards the backfill, a state of seismic passive earth pressure is developed inside the backfill soil. The same is shown in Fig. 18(a) at time $t=4.5 \mathrm{~s}$. The same trends are true for the rotation of the top of the raining wall 
as well - it rotates to a maximum value in the active direction at time $t=3.8 \mathrm{~s}$ (Fig. 16) which corresponds to the maximum seismic active earth pressure (Fig. 18(a)); and similarly it rotates to a maximum value in the passive direction at time $t=4.5 \mathrm{~s}$ (Fig. 16) which corresponds to the maximum seismic passive earth pressure (Fig. 18(a)).

\section{Parametric study}

As observed above, the development of the seismic earth pressure force $P$ is significantly affected by the magnitude and direction of the horizontal displacement and rotation of the retaining wall. In addition, it is observed that the seismic active earth pressure is overestimated by using the MO and pseudo-dynamic methods. To investigate the effect of various factors involved in the above analysis, a parametric study has been carried out by varying the relative density of the backfill and foundation soils, height of the retaining wall, amplitude of the seismic input motion, and frequency content of the seismic loading. For this purpose the results from above FE model have been obtained by varying the abovementioned parameters to capture the following:

- The maximum horizontal displacement at the top of the retaining wall (location $t_{\mathrm{w}}$ );

- The relative horizontal displacement between the centre of gravity of the retaining wall (location $\mathrm{CG}$ ) and a point $0.5 \mathrm{~m}$ below the base of the retaining wall (location $b_{\mathrm{f}}$ );

- The rotation of the retaining wall $\theta$;

- The residual rotation;

- The maximum acceleration at the centre of gravity of the retaining wall (CG);

- The maximum horizontal seismic inertia force of the retaining wall $F$; and

- $\quad$ The seismic active, passive and residual earth pressure forces $P_{\mathrm{ae}}, P_{\mathrm{pe}}$, and $P_{\mathrm{re}}$. 


\subsection{Effect of the relative density of the backfill soil}

Three typical relative densities $\left(D_{\mathrm{r}}\right)$ of the backfill soil have been chosen to replicate loose $\left(D_{\mathrm{r}}\right.$ $=40 \%)$, medium-dense $\left(D_{\mathrm{r}}=65 \%\right)$, and dense $\left(D_{\mathrm{r}}=88 \%\right)$ states of the backfill soil. Table 3 shows the results obtained from the FE analysis. It is observed from Table 3 that the displacement of the top of the retaining wall (location $t_{\mathrm{w}}$ ), relative horizontal displacement between the centre of gravity of the retaining wall (location $\mathrm{CG}$ ) and a point $0.5 \mathrm{~m}$ below the base of the retaining wall (location $b_{\mathrm{f}}$ ), and rotation of the retaining wall have their lowest values when the backfill soil is loose. Similar observations have been reported by [40]. Also, it is observed that the maximum acceleration at the centre of gravity of the retaining wall (location CG) and maximum horizontal seismic inertia force of the retaining wall $F$ do not get affected by the relative density $\left(D_{\mathrm{r}}\right)$ of the backfill soil. For a dense backfill soil seismic active and passive earth pressure values are less than those obtained for a loose backfill soil. However, it is noted that residual seismic earth pressure force $P_{\text {re }}$ increases when the relative density of the backfill soil increases from $40 \%$ to $88 \%$. For all three typical relative densities, the conventional MO theory is overestimating the seismic earth pressure force $P$.

\subsection{Effect of the foundation soil material}

The foundation soil has been modelled for three different materials: medium-dense soil $\left(D_{\mathrm{r}}=\right.$ $50 \%)$, stiff soil $\left(D_{\mathrm{r}}=90 \%\right)$ and rock material. The results obtained from the FE analysis are shown in Table 4. It is observed that the maximum horizontal displacement at the top of retaining wall (location $t_{\mathrm{w}}$ ) and the relative horizontal displacement between the centre of gravity of the retaining wall (location CG) and a point $0.5 \mathrm{~m}$ below the base of the retaining wall (location $b_{\mathrm{f}}$ ) remains almost unchanged when the material of the foundation soil is changed to replicate different states of the foundation soil. On the other hand, the rotation of the retaining wall increases by almost 3 times when the foundation material is changed from rock material to loose soil. A change in the 
material of the foundation soil does not seem to have a significant effect on the seismic active earth pressure force. However, it is observed that the seismic passive earth pressure force increases by about $10 \%$ when the material of the foundation layer is changed from medium-dense soil to a rock material.

\subsection{Effect of the height of the retaining wall}

For the FE analysis, three heights of the retaining walls have been considered, viz., $4 \mathrm{~m}, 8 \mathrm{~m}$, and $12 \mathrm{~m}$. From Table 5 it is observed that the horizontal displacement at the top of the retaining wall (location $t_{\mathrm{w}}$ ), relative horizontal displacement between the centre of gravity of the retaining wall (location CG) and a point $0.5 \mathrm{~m}$ below the base of the retaining wall (location $b_{\mathrm{f}}$ ), and rotation of the retaining wall increase with increasing height of the retaining wall. It is interesting to note that the maximum acceleration at the centre of gravity of the retaining wall $(\mathrm{CG})$ decreases with increasing height of the retaining wall. Further, the amplification of the acceleration towards the top of the retaining wall is more pronounced for a shorter height retaining wall than it is for a relatively high retaining wall. Further, the maximum horizontal seismic inertia force of the retaining wall $F$ increases significantly with increase in the height of the retaining wall. On the other hand, for the seismic earth pressure force, it is observed that the seismic active earth pressure force $P_{\text {ae }}$ for all retaining wall heights is close to the static active earth pressure force $P_{\mathrm{a}}$. However, for the passive case, the seismic passive earth pressure force $P_{\mathrm{pe}}$ is increased with increasing the height of the retaining wall. It is also observed that the residual seismic earth pressure force $P_{\text {re }}$ increases with an increase in the retaining wall height. Further, it is noted that the MO method is overestimating both the seismic active and passive earth pressure forces for all heights of the retaining wall. 


\subsection{Effect of the amplitude of the seismic input motion}

As discussed earlier, a seismic input motion of the real earthquake-time history of the Loma Prieta (1989) earthquake (see Fig. 5) has been used - however, for the purpose of studying the effect of the amplitude of this motion; it is scaled to vary between 0 to $0.6 g$. These acceleration levels are applied for three heights of the retaining wall $(4 \mathrm{~m}, 8 \mathrm{~m}$, and $12 \mathrm{~m})$. As shown in Table 6 , it is observed that the relative horizontal displacement between the centre of gravity of the retaining wall (location $\mathrm{CG}$ ) and a reference point $0.5 \mathrm{~m}$ below the base of the retaining wall (location $b_{\mathrm{f}}$ ) increases significantly with an increase in the acceleration level for all the three retaining wall heights. The maximum horizontal seismic inertia force of the retaining wall $F$ increases drastically for acceleration levels up to about $0.4 g$. For strong earthquake motions, i.e., for acceleration levels between $0.4 g$ to $0.6 g$, the horizontal seismic inertia force of the retaining wall $F$ does not increase at the same rate. This may be because of de-amplification of the acceleration for strong earthquake motion. This observation of de-amplification of the acceleration for strong earthquake motion matches well with previous studies like [56, 57]. It is also interesting to note that for all the acceleration levels, the seismic active earth pressure force $P_{\mathrm{ae}}$ remains almost constant - and its value remains very close to the static active earth pressure force $P_{\mathrm{a}}$. As already discussed, this is in contrast to the conventional MO theory, which inherently assumes that the seismic active earth pressure force $P_{\mathrm{ae}}$ increases with an increase in the acceleration level. However, for the passive case, the seismic passive earth pressure force $P_{\text {pe }}$ increases with increasing acceleration levels up to $0.4 g$, and after that, there is no appreciable increment in the seismic passive earth pressure force $P_{\text {pe }}$. This could be because both the horizontal displacement of the top of the retaining wall (location $t_{\mathrm{w}}$ ) and the maximum seismic passive earth pressure force $P_{\mathrm{pe}}$ are significantly influenced by the local site effects - amplification of low and moderate seismic input motion and de-amplification of the strong seismic input motion. It is also observed that the residual seismic earth pressure force $P_{\text {re }}$ almost remains unchanged with a change in the acceleration level. 


\subsection{Effect of the frequency content of the seismic input motion}

The frequency content of the seismic input motion is investigated by applying uniform sinusoidal acceleration-time histories at the base of the FE model. Each uniform sinusoidal acceleration-time history has 8 cycles. They are scaled to achieve three different amplitudes of $0.2 g, 0.4 g$, and $0.6 g$. For the same amplitude, five uniform acceleration time histories are defined by five frequencies, viz., $0.3 \mathrm{~Hz}, 0.6 \mathrm{~Hz}, 1 \mathrm{~Hz}, 2 \mathrm{~Hz}$, and $3 \mathrm{~Hz}$. Table 7 shows the typical results obtained for the three acceleration amplitudes $0.2 g, 0.4 g$, and $0.6 g$, respectively. It is observed that for the three chosen acceleration amplitudes, the maximum horizontal displacement at the top of the retaining wall (location $t_{\mathrm{w}}$ ), relative horizontal displacement between the centre of gravity of the retaining wall (location CG) and a reference point $0.5 \mathrm{~m}$ below the base of the retaining wall (location $b_{\mathrm{f}}$ ); and rotation of the retaining wall decrease with an increase in the frequency content of the seismic input motion. It is also observed that the seismic active earth pressure force $P_{\mathrm{ae}}$ is still close to the static active earth pressure force $P_{\mathrm{a}}$ even with a change in the frequency content of the seismic input motion. It is because the active earth pressure required a very small displacement to achieve the active state. It can be noted from the results in Table 7 that the active state is achieved by lowest acceleration amplitude and highest frequency content of the seismic input motion. However, for the passive case, the seismic passive earth pressure force decreases remarkably with an increase in the frequency content of the seismic input motion - this is because the passive earth pressure requires a much higher displacement than that in the active case. Hence, it can be noted from the results shown in Table 7 that the seismic passive earth pressure is a function of the acceleration amplitude and frequency content of the seismic input motion. 


\section{Design chart showing a relationship between seismic earth pressure and horizontal wall}

\section{displacement}

From the above results, a relationship between the seismic earth pressure and the displacement of the top of retaining wall has been developed as shown in Figs. 21(a) and 22(a). It is important to observe that as discussed in Section 5.7, the seismic earth pressure is significantly affected by the relative displacement between the retaining wall and backfill soil; however, as (1) this relative displacement is very small (as an example see Fig. 15(b)), and (2) difficult to record during the laboratory experiments and as well as in field, the relationship between seismic earth pressure and displacement has been developed considering the displacement of the top of retaining wall in the proposed design charts (Figs. 21(a) and 22(a)).

The design charts in Fig. 21(a), produced for three wall heights (4 m, $8 \mathrm{~m}$ and $12 \mathrm{~m}$ ), show the relationship between the seismic active and passive earth pressure and the displacement of the top of the retaining wall for acceleration amplitudes varying between $0.1 g-0.6 g$. It is observed from Fig. 21(a) that the relationship between the seismic active earth pressure and displacement of the top of the retaining wall is proportional to the height of the retaining wall. An increase in the height of the retaining wall leads to an increase in the seismic active and passive earth pressure with the same displacement response predicted at the top of the retaining wall. From Fig. 21(b), which presents a relationship between the permanent displacement (sliding) of retaining wall and acceleration amplitude for different retaining wall heights $(4 \mathrm{~m}, 8 \mathrm{~m}$, and $12 \mathrm{~m})$, it is observed that an increase in the height of the retaining wall leads to a significant increase in the permanent displacement of the retaining wall.

Fig. 22(a) presents a relationship between the seismic earth pressure and the displacement of the top of the retaining wall under different acceleration amplitudes and frequency content of the seismic input motion. For the active earth pressure case, it appears that both the acceleration amplitude and frequency content of the seismic input motion do not affect the seismic earth 
pressure versus wall displacement relationship. On the other hand, for the passive case, both the amplitude and frequency of the seismic input motion significantly affects the displacement of the top of the retaining wall and hence the seismic earth pressure. From Fig. 22(a), it is observed that a decrease of frequency content leads to the development of a higher seismic passive earth pressure and larger displacement for the same acceleration amplitude. Fig. 22(b) shows a relationship between the permanent displacement (sliding) of the retaining wall and acceleration amplitude for different frequency content of the seismic input motion. It is also clear from Fig. 22(b) that the permanent displacement of the retaining wall is remarkably affected by the frequency content of the seismic input motion. At the same acceleration amplitude, the retaining wall slides to a much larger displacement when the seismic input motion is applied with low frequency content.

\section{Conclusion}

A FE model of a retaining wall is constructed to produce unique design charts correlating the development of the seismic earth pressure with the movement of the retaining wall. In the FE model, the soil is simulated by using a hardening soil model from the PLAXIS2D library [49], which is a versatile soil constitutive relationship model that takes into account the stressdependency of the soil stiffness, nonlinear shear modulus reduction at very shear strain level, and generation of the hysteretic damping. The proposed FE model of the retaining wall is validated with two centrifuge test results, and the comparison shows that the FE model is successful to replicate the real behaviour of the retaining wall during the earthquake. From the computational results in this study, it is found that the displacement of the retaining wall away from the backfill soil is not affected by the seismic earth pressure force, rather it is the static earth pressure force combined with the horizontal seismic inertia force of the retaining wall $F$ which controls the displacement of the retaining wall. However, the displacement of the retaining wall towards the 
backfill soil is controlled by the horizontal seismic inertia force of the retaining wall $F$ and as well as the seismic passive earth pressure force. It is found that the phase difference between the retaining wall and backfill soil response and soil-structure interaction have a significant influence on the previous observations. Further, from the study, it has again been stressed that the forcebased methods overestimate the seismic active and passive earth pressure forces.

A parametric study was performed in order to investigate the effect of a wide range of parameters on the relationship between the seismic earth pressure and the movement of the retaining wall. The major findings of this parametric study are that the rotation of the retaining wall is highly sensitive to the foundation soil deformability in contrast to the horizontal displacement of the retaining wall. The three different heights of the retaining wall show similar observations. It is also found that there is a clear relationship between the seismic earth pressure force and the displacement of the retaining wall for acceleration level up to about $0.4 \mathrm{~g}$. For strong earthquake motions, i.e., for acceleration level $>0.4 g$, the retaining wall still slides, but without any increment in the seismic passive earth pressure force; primarily under the influence of the horizontal seismic inertia force of the retaining wall $F$. This reflects that the previous variables are significantly influenced by local site effects - amplification of low and moderate seismic input motion and de-amplification of a strong seismic input motion. It is also noted that the seismic active pressure force is close to the static earth pressure force for different acceleration levels, which is in contrast to the conventional force-based MO theory. It is also noted that the frequency content has a significant effect on the relationship between the seismic earth pressures and movement of the retaining wall. It is observed that the maximum displacement and maximum seismic passive earth pressure is shown at the minimum frequency content of the seismic input motion while the seismic active earth pressure is observed to be insensitive to the frequency content of the seismic input motion. 
Unique design charts were derived showing the relationship between the seismic earth pressure and the movement of the retaining wall by taking into account the effects of the height of the retaining wall, acceleration level, and frequency content of the seismic input motion. From the geotechnical engineering perspective, the rigid retaining wall is classified thick, which does not bend. Hence, it can resist the development of seismic passive earth pressure force when it is moving towards the backfill soil. However, this case is extremely critical for the structural design of a cantilever type retaining wall and as well as for the stability of embedded retaining walls. Further investigations are required for understanding the seismic stability of these critical and important geotechnical structures.

\section{Appendix A}

For the FE models of the 2 centrifuge tests, a static FE analysis was performed to decide upon the size of the FE mesh. To do this a mesh size sensitivity analysis was carried out until a fairly convergent solution was achieved. The static earth pressure force was chosen to be the parameter for the sensitivity analysis. The results of the sensitivity analysis are discussed below. Fig. A1 shows that with a reduction in the FE size the static earth pressure force increases very rapidly until about the FE size is $0.5 \mathrm{~m}$. When the element size is reduced further, there is no appreciable increase in the static earth pressure force. An element size of $0.5 \mathrm{~m}$ also complies with the recommendations of [51], as deduced by Eq. (1). Hence, for analysis, the minimum size of the elements was chosen to be $0.5 \mathrm{~m}$. As depicted in Fig. A1, it is to be noted that the static earth pressure force obtained for the optimum FE mesh size of $0.5 \mathrm{~m}$ also compares very well with the results obtained from the Coulomb's and Rankine's earth pressure solutions. 
Table 1: Soil and retaining wall parameters chosen for the FE model to simulate the Saito et al.

$$
\text { (see [50]) and Nakamura [48] centrifuge tests }
$$

\begin{tabular}{|c|c|c|c|c|}
\hline \multirow{2}{*}{ Parameter } & \multirow{2}{*}{ Symbol } & \multirow{2}{*}{ Unit } & \multicolumn{2}{|c|}{ FE model for the centrifuge test by: } \\
\hline & & & Nakamura [48] & Saito et al. (see [50]) \\
\hline \multicolumn{5}{|l|}{ Soil } \\
\hline Relative density & $D_{\mathrm{r}}$ & $\%$ & 88 & 82 \\
\hline Unit weight & $\gamma_{\mathrm{s}}$ & $\mathrm{kN} / \mathrm{m}^{3}$ & 16 & 16 \\
\hline Effective friction angle & $\phi^{\prime}$ & o & 41 & 41 \\
\hline $\begin{array}{l}\text { Modulus at } 50 \% \text { strength at } \\
\text { failure, corresponding to } p^{\text {ref }}\end{array}$ & $E_{50}^{\text {ref }}$ & $\mathrm{MPa}$ & 66.7 & 62.4 \\
\hline $\begin{array}{l}\text { Modulus from an oedometer } \\
\text { test, corresponding to } p^{\text {ref }}\end{array}$ & $E_{\text {oed }}^{\text {ref }}$ & $\mathrm{MPa}$ & 66.7 & 62.4 \\
\hline $\begin{array}{l}\text { Modulus for unloading- } \\
\text { reloading conditions, } \\
\text { corresponding to } p^{\text {ref }}\end{array}$ & $E_{\mathrm{ur}}^{\mathrm{ref}}$ & $\mathrm{MPa}$ & 200 & 187.2 \\
\hline Dilatancy & $\psi$ & o & 11 & 11 \\
\hline $\begin{array}{l}\text { Poisson's ratio for unloading- } \\
\text { reloading conditions }\end{array}$ & $v_{\mathrm{ur}}$ & - & 0.25 & 0.25 \\
\hline $\begin{array}{l}\text { A constant, to account for the } \\
\text { stiffness stress-level } \\
\text { dependency }\end{array}$ & $y$ & - & 0.55 & 0.55 \\
\hline $\begin{array}{l}\text { Initial small strain shear } \\
\text { modulus of the soil, } \\
\text { corresponding to } p^{\text {ref }}\end{array}$ & $G_{0}^{\mathrm{ref}}$ & $\mathrm{MPa}$ & 150 & 144 \\
\hline $\begin{array}{l}\text { Reference shear strain, } \\
\text { corresponding to } 70 \% \text { of } G_{0}^{\text {ref }}\end{array}$ & $\gamma_{0.7}$ & - & 0.0003 & 0.0003 \\
\hline Reference confining pressure & $p^{\mathrm{ref}}$ & $\mathrm{kN} / \mathrm{m}^{2}$ & 100 & 100 \\
\hline Damping ratio & $\xi$ & $\%$ & 3 & 3 \\
\hline Failure ratio & $R_{\mathrm{f}}$ & - & 0.9 & 0.9 \\
\hline \multicolumn{5}{|l|}{ Retaining wall } \\
\hline Modulus of elasticity & $E$ & $\mathrm{MPa}$ & 30000 & 30000 \\
\hline Poisson's ratio & $v$ & - & 0.15 & 0.15 \\
\hline Unit weight & $\gamma_{\mathrm{w}}$ & $\mathrm{kN} / \mathrm{m}^{3}$ & 18 & 18 \\
\hline Damping ratio & $\xi$ & $\%$ & 3 & 3 \\
\hline
\end{tabular}


Table 2: Soil and retaining wall properties and other parameters used for the present study

\begin{tabular}{|c|c|c|c|c|c|c|}
\hline \multirow{2}{*}{ Parameter } & \multirow{2}{*}{ Symbol } & \multirow{2}{*}{ Unit } & \multicolumn{3}{|c|}{ Backfill soil } & \multirow{2}{*}{$\begin{array}{c}\text { Foundation } \\
\text { soil }\end{array}$} \\
\hline & & & Base value & Loose & Dense & \\
\hline \multicolumn{7}{|l|}{ Soil } \\
\hline Relative density & $D_{\mathrm{r}}$ & $\%$ & 65 & 40 & 88 & 95 \\
\hline Unit weight & $\gamma_{\mathrm{s}}$ & $\mathrm{kN} / \mathrm{m}^{3}$ & 19 & 16 & 19 & 19 \\
\hline Effective friction angle & $\phi^{\prime}$ & o & 35 & 33 & 39 & 38 \\
\hline $\begin{array}{l}\text { Modulus at } 50 \% \text { strength at } \\
\text { failure, corresponding to } \\
p^{\text {ref }}\end{array}$ & $E_{50}^{\mathrm{ref}}$ & $\mathrm{MPa}$ & 45 & 24 & 51 & 105 \\
\hline $\begin{array}{l}\text { Modulus from an oedometer } \\
\text { test, corresponding to } p^{\text {ref }}\end{array}$ & $E_{\text {oed }}^{\text {ref }}$ & $\mathrm{MPa}$ & 45 & 24 & 51 & 105 \\
\hline $\begin{array}{l}\text { Modulus for unloading- } \\
\text { reloading conditions, } \\
\text { corresponding to } p^{\text {ref }}\end{array}$ & $E_{\mathrm{ur}}^{\mathrm{ref}}$ & $\mathrm{MPa}$ & 180 & 96 & 204 & 315 \\
\hline Dilatancy & $\psi$ & o & 5 & 3 & 1 & 6 \\
\hline $\begin{array}{l}\text { Poisson's ratio for } \\
\text { unloading-reloading } \\
\text { conditions }\end{array}$ & $v_{\mathrm{ur}}$ & - & 0.2 & 0.2 & 39 & 0.2 \\
\hline $\begin{array}{l}\text { A constant, to account for } \\
\text { the stiffness stress-level } \\
\text { dependency }\end{array}$ & $y$ & - & 0.55 & 0.55 & 9 & 0.55 \\
\hline $\begin{array}{l}\text { Initial small strain shear } \\
\text { modulus, corresponding to } \\
p^{\text {ref }}\end{array}$ & $G_{\mathrm{o}}^{\mathrm{ref}}$ & $\mathrm{MPa}$ & 168.75 & 102.4 & 217.6 & - \\
\hline $\begin{array}{l}\text { Reference shear strain, } \\
\text { corresponding to } 70 \% \text { of } \\
G_{0}^{\text {ref }}\end{array}$ & $\gamma_{0.7}$ & - & 0.0002 & 0.0002 & 0.0002 & - \\
\hline $\begin{array}{l}\text { Reference confining } \\
\text { pressure }\end{array}$ & $p^{\mathrm{ref}}$ & $\mathrm{kN} / \mathrm{m}^{2}$ & 100 & 100 & 100 & 100 \\
\hline Damping ratio & $\xi$ & $\%$ & 3 & 3 & 3 & 3 \\
\hline Failure ratio & $R_{\mathrm{f}}$ & - & 0.9 & 0.9 & 0.9 & 0.9 \\
\hline \multicolumn{7}{|l|}{ Retaining wall } \\
\hline Modulus of elasticity & $E$ & $\mathrm{MPa}$ & 30000 & & & \\
\hline Poisson's ratio & $v$ & - & 0.15 & & & \\
\hline Unit weight & $\gamma_{\mathrm{w}}$ & $\mathrm{kN} / \mathrm{m}^{3}$ & 24 & & & \\
\hline Damping ratio & $\xi$ & $\%$ & 3 & & & \\
\hline
\end{tabular}


Table 3: Effect of the relative density of the backfill soil

\begin{tabular}{|c|c|c|c|c|c|c|c|c|c|c|c|c|c|c|c|c|}
\hline \multirow{3}{*}{$\begin{array}{l}D_{\mathrm{r}} \\
(\%)\end{array}$} & \multicolumn{3}{|c|}{ Horizontal displacement (m) } & \multicolumn{3}{|c|}{ Rotation (degree) } & \multicolumn{4}{|c|}{$\begin{array}{l}\text { Acceleration }(g) \text { and horizontal } \\
\text { seismic inertia force }(\mathrm{kN} / \mathrm{m})\end{array}$} & \multicolumn{4}{|c|}{$\begin{array}{l}\text { Seismic earth pressure force } \\
\text { from the FE model }(\mathrm{kN} / \mathrm{m})\end{array}$} & \multicolumn{2}{|c|}{$\begin{array}{l}\text { Seismic earth } \\
\text { pressure force } \\
\text { from the } \mathrm{MO} \\
\text { theory }(\mathrm{kN} / \mathrm{m})\end{array}$} \\
\hline & \multicolumn{2}{|c|}{ At location $t_{\mathrm{w}}$} & \multirow{2}{*}{$\begin{array}{l}\text { Between } \\
\text { locations } \\
\text { CG and } b_{\mathrm{f}}\end{array}$} & \multirow{2}{*}{$\begin{array}{l}\text { Active } \\
\text { direction }\end{array}$} & \multirow{2}{*}{$\begin{array}{l}\text { Passive } \\
\text { direction }\end{array}$} & \multirow{2}{*}{$\begin{array}{l}\text { Residual } \\
\text { permanent } \\
\text { rotation }\end{array}$} & \multicolumn{2}{|c|}{$\begin{array}{l}\text { Active } \\
\text { direction }\end{array}$} & \multicolumn{2}{|c|}{$\begin{array}{l}\text { Passive } \\
\text { direction }\end{array}$} & \multirow{2}{*}{$P_{\mathrm{a}}$} & \multirow{2}{*}{$P_{\mathrm{ae}}$} & \multirow{2}{*}{$P_{\mathrm{pe}}$} & \multirow{2}{*}{$P_{\text {re }}$} & \multirow{2}{*}{$P_{\mathrm{ae}}$} & \multirow{2}{*}{$P_{\mathrm{pe}}$} \\
\hline & $\begin{array}{l}\text { Active } \\
\text { direction }\end{array}$ & $\begin{array}{l}\text { Passive } \\
\text { direction }\end{array}$ & & & & & $a_{\mathrm{CG}}$ & $F_{\mathrm{a}}$ & $a_{\mathrm{CG}}$ & $F_{\mathrm{p}}$ & & & & & & \\
\hline 40 & 0.163 & 0.114 & 0.021 & 0.054 & 0.049 & 0.109 & 0.345 & 75.12 & 0.590 & 128.7 & 43.28 & 44.28 & 108.40 & 59.46 & 59.92 & 625.70 \\
\hline 65 & 0.168 & 0.116 & 0.025 & 0.083 & 0.073 & 0.123 & 0.346 & 75.79 & 0.654 & 124.9 & 44.10 & 42.51 & 103.90 & 65.15 & 66.45 & 883.28 \\
\hline 88 & 0.179 & 0.131 & 0.036 & 0.103 & 0.172 & 0.138 & 0.346 & 75.79 & 0.590 & 128.7 & 44.23 & 40.57 & 95.62 & 69.43 & 58.09 & 1296.20 \\
\hline
\end{tabular}


Table 4: Effect of the foundation soil material

\begin{tabular}{|c|c|c|c|c|c|c|c|c|c|c|c|c|c|c|c|c|}
\hline \multirow{3}{*}{$\begin{array}{l}D_{\mathrm{r}} \\
(\%)\end{array}$} & \multicolumn{3}{|c|}{ Horizontal displacement (m) } & \multicolumn{3}{|c|}{ Rotation (degree) } & \multicolumn{4}{|c|}{$\begin{array}{l}\text { Acceleration }(g) \text { and horizontal } \\
\text { seismic inertia force }(\mathrm{kN} / \mathrm{m})\end{array}$} & \multicolumn{4}{|c|}{$\begin{array}{l}\text { Seismic earth pressure force } \\
\text { from the FE model }(\mathrm{kN} / \mathrm{m})\end{array}$} & \multicolumn{2}{|c|}{$\begin{array}{l}\text { Seismic earth } \\
\text { pressure force } \\
\text { from the MO } \\
\text { theory }(\mathrm{kN} / \mathrm{m})\end{array}$} \\
\hline & \multicolumn{2}{|c|}{ At location $t_{\mathrm{w}}$} & \multirow{2}{*}{$\begin{array}{l}\text { Between } \\
\text { locations } \\
\text { CG and } b_{\mathrm{f}}\end{array}$} & \multirow{2}{*}{$\begin{array}{l}\text { Active } \\
\text { direction }\end{array}$} & \multirow{2}{*}{$\begin{array}{l}\text { Passive } \\
\text { direction }\end{array}$} & \multirow{2}{*}{$\begin{array}{l}\text { Residual } \\
\text { permanent } \\
\text { rotation }\end{array}$} & \multicolumn{2}{|c|}{$\begin{array}{l}\text { Active } \\
\text { direction }\end{array}$} & \multicolumn{2}{|c|}{$\begin{array}{l}\text { Passive } \\
\text { direction }\end{array}$} & \multirow{2}{*}{$P_{\mathrm{a}}$} & \multirow{2}{*}{$P_{\mathrm{ae}}$} & \multirow{2}{*}{$P_{\mathrm{pe}}$} & \multirow{2}{*}{$P_{\text {re }}$} & \multirow{2}{*}{$P_{\mathrm{ae}}$} & \multirow{2}{*}{$P_{\mathrm{pe}}$} \\
\hline & $\begin{array}{l}\text { Active } \\
\text { direction }\end{array}$ & $\begin{array}{l}\text { Passive } \\
\text { direction }\end{array}$ & & & & & $a_{\mathrm{CG}}$ & $F_{\mathrm{a}}$ & $a_{\mathrm{CG}}$ & $F_{\mathrm{p}}$ & & & & & & \\
\hline 50 & 0.166 & 0.118 & 0.023 & 0.083 & 0.046 & 0.136 & 0.344 & 74.88 & 0.570 & 124.7 & 44.44 & 44.13 & 98.8 & 67.18 & 66.45 & 883.28 \\
\hline 90 & 0.168 & 0.116 & 0.025 & 0.083 & 0.073 & 0.123 & 0.346 & 75.79 & 0.654 & 124.9 & 44.10 & 42.51 & 103.9 & 65.15 & 66.45 & 883.28 \\
\hline Rock & 0.159 & 0.121 & 0.021 & 0.025 & 0.035 & 0.041 & 0.343 & 75.56 & 0.587 & 128.4 & 45.37 & 44.36 & 117.1 & 63.54 & 66.45 & 883.28 \\
\hline
\end{tabular}


Table 5: Effect of the height of the retaining wall

\begin{tabular}{|c|c|c|c|c|c|c|c|c|c|c|c|c|c|c|c|c|}
\hline \multirow{3}{*}{$\begin{array}{l}H \\
(\mathrm{~m})\end{array}$} & \multicolumn{3}{|c|}{ Horizontal displacement (m) } & \multicolumn{3}{|c|}{ Rotation (degree) } & \multicolumn{4}{|c|}{$\begin{array}{l}\text { Acceleration }(g) \text { and horizontal } \\
\text { seismic inertia force }(\mathrm{kN} / \mathrm{m})\end{array}$} & \multicolumn{4}{|c|}{$\begin{array}{l}\text { Seismic earth pressure force } \\
\text { from the FE model }(\mathrm{kN} / \mathrm{m})\end{array}$} & \multicolumn{2}{|c|}{$\begin{array}{l}\text { Seismic earth } \\
\text { pressure force } \\
\text { from the } \mathrm{MO} \\
\text { theory }(\mathrm{kN} / \mathrm{m})\end{array}$} \\
\hline & \multicolumn{2}{|c|}{ At location $t_{\mathrm{w}}$} & \multirow{2}{*}{$\begin{array}{l}\text { Between } \\
\text { locations } \\
\text { CG and } b_{\mathrm{f}}\end{array}$} & \multirow{2}{*}{$\begin{array}{l}\text { Active } \\
\text { direction }\end{array}$} & \multirow{2}{*}{$\begin{array}{l}\text { Passive } \\
\text { direction }\end{array}$} & \multirow{2}{*}{$\begin{array}{l}\text { Residual } \\
\text { permanent } \\
\text { rotation }\end{array}$} & \multicolumn{2}{|c|}{$\begin{array}{l}\text { Active } \\
\text { direction }\end{array}$} & \multicolumn{2}{|c|}{$\begin{array}{l}\text { Passive } \\
\text { direction }\end{array}$} & \multirow{2}{*}{$P_{\mathrm{a}}$} & \multirow{2}{*}{$P_{\mathrm{ae}}$} & \multirow{2}{*}{$P_{\mathrm{pe}}$} & \multirow{2}{*}{$P_{\text {re }}$} & \multirow{2}{*}{$P_{\mathrm{ae}}$} & \multirow{2}{*}{$P_{\mathrm{pe}}$} \\
\hline & $\begin{array}{l}\text { Active } \\
\text { direction }\end{array}$ & $\begin{array}{l}\text { Passive } \\
\text { direction }\end{array}$ & & & & & $a_{\mathrm{CG}}$ & $F_{\mathrm{a}}$ & $a_{\mathrm{CG}}$ & $F_{\mathrm{p}}$ & & & & & & \\
\hline 4 & 0.163 & 0.116 & 0.031 & 0.074 & 0.051 & 0.123 & 0.346 & 75.79 & 0.654 & 124.9 & 44.1 & 48.51 & 103.9 & 65.15 & 66.45 & 883.2 \\
\hline 8 & 0.189 & 0.127 & 0.061 & 0.188 & 0.011 & 0.309 & 0.261 & 162.2 & 0.529 & 330.1 & 186.9 & 180.8 & 361.1 & 242.3 & 265.9 & 3533 \\
\hline 12 & 0.235 & 0.129 & 0.185 & 0.419 & 0.091 & 0.958 & 0.237 & 255.9 & 0.451 & 487.2 & 275.1 & 251.2 & 583.6 & 364.8 & 598.4 & 7949 \\
\hline
\end{tabular}


Table 6: Effect of the amplitude of seismic input motion for different wall heights

\begin{tabular}{|c|c|c|c|c|c|c|c|c|c|c|c|c|c|c|c|c|}
\hline \multirow{3}{*}{$a(\mathrm{~g})$} & \multicolumn{3}{|c|}{ Horizontal displacement (m) } & \multicolumn{3}{|c|}{ Rotation (degree) } & \multicolumn{4}{|c|}{$\begin{array}{l}\text { Acceleration }(g) \text { and horizontal } \\
\text { seismic inertia force }(\mathrm{kN} / \mathrm{m})\end{array}$} & \multicolumn{4}{|c|}{$\begin{array}{l}\text { Seismic earth pressure force } \\
\text { from the FE model }(\mathrm{kN} / \mathrm{m})\end{array}$} & \multicolumn{2}{|c|}{$\begin{array}{l}\text { Seismic earth } \\
\text { pressure force } \\
\text { from the } \mathrm{MO} \\
\text { theory }(\mathrm{kN} / \mathrm{m})\end{array}$} \\
\hline & \multicolumn{2}{|c|}{ At location $t_{\mathrm{w}}$} & \multirow{2}{*}{$\begin{array}{l}\text { Between } \\
\text { locations } \\
\text { CG and } b_{\mathrm{f}}\end{array}$} & \multirow{2}{*}{$\begin{array}{l}\text { Active } \\
\text { direction }\end{array}$} & \multirow{2}{*}{$\begin{array}{l}\text { Passive } \\
\text { direction }\end{array}$} & \multirow{2}{*}{$\begin{array}{l}\text { Residual } \\
\text { permanent } \\
\text { rotation }\end{array}$} & \multicolumn{2}{|c|}{$\begin{array}{l}\text { Active } \\
\text { direction }\end{array}$} & \multicolumn{2}{|c|}{$\begin{array}{l}\text { Passive } \\
\text { direction }\end{array}$} & \multirow{2}{*}{$P_{\mathrm{a}}$} & \multirow{2}{*}{$P_{\mathrm{ae}}$} & \multirow{2}{*}{$P_{\mathrm{pe}}$} & \multirow{2}{*}{$P_{\text {re }}$} & \multirow{2}{*}{$P_{\mathrm{ae}}$} & \multirow{2}{*}{$P_{\mathrm{pe}}$} \\
\hline & $\begin{array}{l}\text { Active } \\
\text { direction }\end{array}$ & $\begin{array}{l}\text { Passive } \\
\text { direction }\end{array}$ & & & & & $a_{\mathrm{CG}}$ & $F_{\mathrm{a}}$ & $a_{\mathrm{CG}}$ & $F_{\mathrm{p}}$ & & & & & & \\
\hline \multicolumn{17}{|c|}{ Height of the retaining wall, $H=4 \mathrm{~m}$} \\
\hline $0.1 \mathrm{~g}$ & 0.064 & 0.047 & 0.003 & 0.048 & 0.022 & 0.035 & 0.222 & 47.01 & 0.252 & 53.25 & 43.28 & 44.13 & 85.32 & 62.34 & 46.45 & 1031 \\
\hline $0.2 \mathrm{~g}$ & 0.129 & 0.091 & 0.011 & 0.074 & 0.045 & 0.096 & 0.331 & 72.21 & 0.443 & 95.04 & 43.28 & 42.11 & 93.11 & 65.35 & 57.72 & 941.9 \\
\hline $0.3 \mathrm{~g}$ & 0.209 & 0.137 & 0.029 & 0.199 & 0.074 & 0.271 & 0.411 & 90.23 & 0.763 & 164.2 & 43.28 & 40.42 & 136.5 & 69.32 & 72.09 & 849.5 \\
\hline $0.4 \mathrm{~g}$ & 0.297 & 0.168 & 0.071 & 0.374 & 0.094 & 0.575 & 0.484 & 96.71 & 0.912 & 196.6 & 43.28 & 37.47 & 148.9 & 72.38 & 91.08 & 752.6 \\
\hline $0.5 \mathrm{~g}$ & 0.391 & 0.169 & 0.162 & 0.665 & 0.137 & 1.221 & 0.532 & 114.5 & 0.951 & 205.2 & 43.28 & 37.22 & 153.2 & 67.89 & 117.6 & 648.1 \\
\hline $0.6 \mathrm{~g}$ & 0.493 & 0.165 & 0.291 & 1.206 & 0.149 & 2.156 & 0.613 & 131.8 & 0.933 & 200.9 & 43.28 & 37.17 & 133.9 & 67.51 & 159.7 & 527.9 \\
\hline \multicolumn{17}{|c|}{ Height of the retaining wall, $H=8 \mathrm{~m}$} \\
\hline $0.1 \mathrm{~g}$ & 0.074 & 0.054 & 0.015 & 0.081 & 0.044 & 0.116 & 0.149 & 92.98 & 0.245 & 152.9 & 187.3 & 192.2 & 258.3 & 240.7 & 185.8 & 4124 \\
\hline $0.2 \mathrm{~g}$ & 0.141 & 0.096 & 0.038 & 0.172 & 0.057 & 0.228 & 0.228 & 142.3 & 0.417 & 260.2 & 187.3 & 188.1 & 322.2 & 240.9 & 230.9 & 3767 \\
\hline $0.3 \mathrm{~g}$ & 0.221 & 0.146 & 0.089 & 0.211 & 0.131 & 0.366 & 0.289 & 180.3 & 0.583 & 363.8 & 187.6 & 173.2 & 366.9 & 267.9 & 288.3 & 3398 \\
\hline $0.4 \mathrm{~g}$ & 0.284 & 0.173 & 0.175 & 0.194 & 0.148 & 0.511 & 0.379 & 236.5 & 0.659 & 411.2 & 187.4 & 175.4 & 384.9 & 298.1 & 364.3 & 3010 \\
\hline $0.5 \mathrm{~g}$ & 0.374 & 0.217 & 0.291 & 0.236 & 0.201 & 0.701 & 0.402 & 250.9 & 0.784 & 489.2 & 187.4 & 165.8 & 402.2 & 302.2 & 470.6 & 2592 \\
\hline $0.6 \mathrm{~g}$ & 0.428 & 0.215 & 0.408 & 0.307 & 0.203 & 0.891 & 0.419 & 261.5 & 0.868 & 541.6 & 187.4 & 184.5 & 406.5 & 304.4 & 639.2 & 2111 \\
\hline \multicolumn{17}{|c|}{ Height of the retaining wall, $H=12 \mathrm{~m}$} \\
\hline $0.1 \mathrm{~g}$ & 0.083 & 0.052 & 0.064 & 0.092 & 0.027 & 0.367 & 0.116 & 125.3 & 0.222 & 239.8 & 359.2 & 351.6 & 558.1 & 409.7 & 418.1 & 9280 \\
\hline $0.2 \mathrm{~g}$ & 0.165 & 0.089 & 0.136 & 0.182 & 0.067 & 0.721 & 0.207 & 223.6 & 0.371 & 400.7 & 359.6 & 352.4 & 672.8 & 433.1 & 519.5 & 8477 \\
\hline $0.3 \mathrm{~g}$ & 0.259 & 0.138 & 0.225 & 0.316 & 0.112 & 1.152 & 0.274 & 295.9 & 0.499 & 538.9 & 359.4 & 334.8 & 768.5 & 439.4 & 648.9 & 7646 \\
\hline $0.4 \mathrm{~g}$ & 0.339 & 0.152 & 0.332 & 0.416 & 0.134 & 1.596 & 0.324 & 349.9 & 0.582 & 628.6 & 359.6 & 324.3 & 853.9 & 484.5 & 819.7 & 6773 \\
\hline $0.5 \mathrm{~g}$ & 0.437 & 0.204 & 0.461 & 0.572 & 0.229 & 2.029 & 0.387 & 417.9 & 0.691 & 746.3 & 359.6 & 322.4 & 897.4 & 519.2 & 1058 & 5832 \\
\hline $0.6 \mathrm{~g}$ & 0.489 & 0.208 & 0.613 & 0.503 & 0.228 & 2.528 & 0.429 & 463.3 & 0.723 & 780.8 & 359.6 & 321.1 & 910.6 & 529.1 & 1438 & 4751 \\
\hline
\end{tabular}


Table 7: Effect of the frequency content of seismic input motion for different amplitudes

\begin{tabular}{|c|c|c|c|c|c|c|c|c|c|c|c|c|c|c|c|c|}
\hline \multirow{3}{*}{$\begin{array}{l}f \\
(\mathrm{~Hz})\end{array}$} & \multicolumn{3}{|c|}{ Horizontal displacement (m) } & \multicolumn{3}{|c|}{ Rotation (degree) } & \multicolumn{4}{|c|}{$\begin{array}{l}\text { Acceleration }(g) \text { and horizontal } \\
\text { seismic inertia force }(\mathrm{kN} / \mathrm{m})\end{array}$} & \multicolumn{4}{|c|}{$\begin{array}{l}\text { Seismic earth pressure force } \\
\text { from the FE model }(\mathrm{kN} / \mathrm{m})\end{array}$} & \multicolumn{2}{|c|}{$\begin{array}{l}\text { Seismic earth } \\
\text { pressure force } \\
\text { from the } \mathrm{MO} \\
\text { theory }(\mathrm{kN} / \mathrm{m})\end{array}$} \\
\hline & \multicolumn{2}{|c|}{ At location $t_{\mathrm{w}}$} & \multirow{2}{*}{$\begin{array}{l}\text { Between } \\
\text { locations } \\
\mathrm{CG} \text { and } b_{\mathrm{f}}\end{array}$} & \multirow{2}{*}{$\begin{array}{l}\text { Active } \\
\text { direction }\end{array}$} & \multirow{2}{*}{$\begin{array}{l}\text { Passive } \\
\text { direction }\end{array}$} & \multirow{2}{*}{$\begin{array}{l}\text { Residual } \\
\text { permanent } \\
\text { rotation }\end{array}$} & \multicolumn{2}{|c|}{$\begin{array}{l}\text { Active } \\
\text { direction }\end{array}$} & \multicolumn{2}{|c|}{$\begin{array}{l}\text { Passive } \\
\text { direction }\end{array}$} & \multirow{2}{*}{$P_{\mathrm{a}}$} & \multirow{2}{*}{$P_{\mathrm{ae}}$} & \multirow{2}{*}{$P_{\mathrm{pe}}$} & \multirow{2}{*}{$P_{\text {re }}$} & \multirow{2}{*}{$P_{\text {ae }}$} & \multirow{2}{*}{$P_{\mathrm{pe}}$} \\
\hline & $\begin{array}{l}\text { Active } \\
\text { direction }\end{array}$ & $\begin{array}{l}\text { Passive } \\
\text { direction }\end{array}$ & & & & & $a_{\mathrm{CG}}$ & $F_{\mathrm{a}}$ & $a_{\mathrm{CG}}$ & $F_{\mathrm{p}}$ & & & & & & \\
\hline \multicolumn{17}{|c|}{ Seismic input motion amplitude, $a=0.2 g$} \\
\hline 0.33 & 0.533 & $0.799^{1}$ & 0.160 & 0.246 & 0.028 & 1.601 & 0.211 & 45.58 & 0.223 & 50.33 & 45.26 & 41.6 & 138.6 & 68.25 & 57.72 & 941.95 \\
\hline 0.66 & 0.139 & 0.237 & 0.013 & 0.037 & 0.026 & 0.131 & 0.213 & 46.11 & 0.251 & 54.22 & 45.26 & 55.17 & 107.5 & 75.75 & 57.72 & 941.95 \\
\hline 1 & 0.067 & 0.104 & 0.014 & 0.039 & 0.027 & 0.144 & 0.231 & 49.89 & 0.231 & 49.89 & 45.26 & 51.50 & 88.74 & 73.16 & 57.72 & 941.95 \\
\hline 2 & 0.021 & 0.031 & 0.011 & & 0.031 & & 0.236 & 50.98 & & 46.44 & 45.26 & 47.36 & 86.48 & 71.23 & 57.72 & 941.95 \\
\hline 3 & 0.017 & 0.017 & 0.032 & 0.037 & 0.027 & 0.113 & 0.232 & 50.11 & 0.236 & 50.98 & 45.26 & 51.48 & 94.37 & 58.23 & 57.72 & 941.95 \\
\hline \multicolumn{17}{|c|}{ Seismic input motion amplitude, $a=0.4 \mathrm{~g}$} \\
\hline 0.33 & 1.050 & $1.170^{\mathrm{T}}$ & 1.361 & 0.862 & 0.077 & 9 & 0.304 & 65.66 & 0. & $10 t$ & 45.26 & 51.68 & 153.1 & 74.16 & 57.72 & 941.95 \\
\hline 0.66 & 0.289 & 0.385 & 0.351 & 0.256 & 8 & 1.721 & 0.312 & 67.39 & 0.472 & 101.9 & 45.26 & 49.82 & 130.8 & 70.54 & 57.72 & 941.95 \\
\hline 1 & 0.137 & 0.188 & 0.219 & 0.123 & 0.054 & 0.604 & 0.313 & 67.61 & 0.405 & 87.48 & 45.26 & 50.91 & 106.1 & 66.08 & 57.72 & 941.95 \\
\hline 2 & 0.048 & 0.051 & 0.135 & 0.091 & 0.077 & 0.174 & 0.319 & 68.91 & 0.489 & 105.6 & 45.26 & 36.66 & 103.3 & 64.67 & 57.72 & 941.95 \\
\hline 3 & 0.042 & 0.019 & 0.222 & 0.105 & 0.091 & 0.132 & 0.445 & 96.12 & 0.722 & 155.9 & 45.26 & 65.52 & 143.8 & 83.69 & 57.72 & 941.95 \\
\hline \multicolumn{17}{|c|}{ Seismic input motion amplitude, $a=0.6 \mathrm{~g}$} \\
\hline 0.33 & 1.464 & $1.517^{1}$ & 3.250 & 1.861 & 0.510 & 11.241 & 0.392 & 84.67 & 0.758 & 163.7 & 45.26 & 51.68 & 153.1 & 74.16 & 57.72 & 941.95 \\
\hline 0.66 & 0.434 & 0.448 & 1.058 & 0.469 & 0.159 & 3.485 & 0.394 & 85.11 & 0.709 & 153.1 & 45.26 & 49.82 & 130.8 & 70.54 & 57.72 & 941.95 \\
\hline 1 & 0.218 & 0.222 & 0.712 & 0.149 & 0.095 & 1.224 & 0.382 & 82.51 & 0.658 & 142.2 & 45.26 & 50.91 & 106.1 & 66.08 & 57.72 & 941.95 \\
\hline 2 & 0.077 & 0.056 & 0.351 & 0.129 & 0.122 & 0.122 & 0.348 & 75.17 & 0.754 & 162.9 & 45.26 & 36.66 & 103.3 & 64.67 & 57.72 & 941.95 \\
\hline 3 & 0.051 & 0.019 & 0.351 & 0.146 & 0.131 & 0.013 & 0.438 & 94.61 & 0.742 & 160.3 & 45.26 & 65.52 & 143.8 & 83.69 & 57.72 & 941.95 \\
\hline
\end{tabular}




\section{List of symbols}

\begin{tabular}{|c|c|}
\hline$a$ & Acceleration \\
\hline$a_{\mathrm{CG}}$ & Acceleration at the centre of gravity of the retaining wall \\
\hline$b_{\mathrm{f}}$ & $\begin{array}{l}\text { A reference point in the foundation soil, located } 0.5 \mathrm{~m} \text { below the base of the } \\
\text { retaining wall }\end{array}$ \\
\hline$b_{\mathrm{m}}$ & A reference point, located at the base of the FE model \\
\hline$b_{\mathrm{w}}$ & A reference point, located at the bottom of the retaining wall \\
\hline$c^{\prime}$ & Effective cohesion of the soil \\
\hline$[\boldsymbol{C}]$ & Damping matrix of the system \\
\hline$d_{\text {active }}$ & Horizontal displacement in the active direction \\
\hline$d_{\text {passive }}$ & Horizontal displacement in the passive direction \\
\hline$D_{\mathrm{r}}$ & Relative density of the soil \\
\hline$E$ & Modulus of elasticity of the wall \\
\hline$E_{50}$ & Modulus of soil at $50 \%$ of the soil's strength at failure \\
\hline$E_{50}^{\mathrm{ref}}$ & $\begin{array}{l}\text { Modulus of soil at } 50 \% \text { of the soil's strength at failure, corresponding to a } \\
\text { reference confining pressure } p^{\text {ref }}\end{array}$ \\
\hline$E_{\mathrm{i}}$ & Initial modulus of the soil \\
\hline$E_{\mathrm{oed}}$ & Modulus of the soil obtained from an oedometer test \\
\hline$E_{\text {oed }}^{\text {ref }}$ & $\begin{array}{l}\text { Modulus of the soil obtained from an oedometer test, corresponding to a } \\
\text { reference confining pressure } p^{\text {ref }}\end{array}$ \\
\hline$E_{\text {ur }}$ & Modulus of the soil for unloading-reloading conditions \\
\hline$E_{\mathrm{ur}}^{\mathrm{ref}}$ & $\begin{array}{l}\text { Modulus of the soil for unloading-reloading conditions, corresponding to a } \\
\text { reference confining pressure } p^{\text {ref }}\end{array}$ \\
\hline$f$ & Frequency of the seismic input motion \\
\hline$f_{\max }$ & Maximum frequency of the seismic input motion \\
\hline
\end{tabular}




\begin{tabular}{|c|c|}
\hline$F$ & Horizontal seismic inertia force of the retaining wall \\
\hline$F_{\mathrm{a}}$ & $\begin{array}{l}\text { Horizontal seismic inertia force of the retaining wall, acting away from the } \\
\text { backfill soil }\end{array}$ \\
\hline$F_{\mathrm{p}}$ & $\begin{array}{l}\text { Horizontal seismic inertia force of the retaining wall, acting towards the } \\
\text { backfill soil }\end{array}$ \\
\hline$g$ & Gravity acceleration \\
\hline$G$ & Shear modulus of the soil \\
\hline$G_{\mathrm{o}}$ & Initial small strain shear modulus of the soil \\
\hline$G_{\mathrm{o}}^{\mathrm{ref}}$ & $\begin{array}{l}\text { Initial small strain shear modulus of the soil, corresponding to a reference } \\
\text { pressure } p^{r e f}\end{array}$ \\
\hline$G_{\mathrm{ur}}$ & Shear modulus of the soil for unloading-reloading conditions \\
\hline$h$ & Thickness of the foundation soil \\
\hline$h_{\mathrm{ei}}$ & Height of the element \\
\hline$h \mathrm{e}_{\max }$ & Maximum height of an element of the FE mesh \\
\hline$H$ & Height of the retaining wall (and backfill soil) \\
\hline$[K]$ & Stiffness matrix of the system \\
\hline$K_{o}$ & At-rest earth pressure coefficient \\
\hline$m$ & Mass of the retaining wall \\
\hline$[M]$ & Mass matrix of the system \\
\hline$n$ & $\begin{array}{l}\text { Number of elements of the backfill soil which are in contact with the back of } \\
\text { the retaining wall }\end{array}$ \\
\hline$p_{\mathrm{a}}$ & Static active earth pressure \\
\hline$p_{\mathrm{ae}}$ & Seismic active earth pressure \\
\hline$p_{\mathrm{o}}$ & Static at-rest earth pressure \\
\hline$p_{\text {pe }}$ & Seismic passive earth pressure \\
\hline
\end{tabular}




\begin{tabular}{|c|c|}
\hline$p^{\text {ref }}$ & Reference confining pressure $\left(=100 \mathrm{kN} / \mathrm{m}^{2}\right)$ \\
\hline$P$ & Seismic earth pressure force \\
\hline$P_{\mathrm{a}}$ & Static active earth pressure force \\
\hline$P_{\mathrm{ae}}$ & Seismic active earth pressure force \\
\hline$P_{\text {ei }}$ & Seismic earth pressure force for the element \\
\hline$P_{\mathrm{o}}$ & Static at-rest earth pressure force \\
\hline$P_{\mathrm{pe}}$ & Seismic passive earth pressure force \\
\hline$P_{\text {re }}$ & Residual seismic earth pressure force \\
\hline$q_{\mathrm{a}}$ & Asymptotic value to the soil's strength at failure \\
\hline$q_{\mathrm{f}}$ & Soil's strength at failure \\
\hline$R_{\mathrm{f}}$ & Failure ratio \\
\hline$t$ & Time \\
\hline$t_{\mathrm{b}}$ & A reference point, located at the top of the backfill soil \\
\hline$t_{\mathrm{w}}$ & A reference point, located at the top of the retaining wall \\
\hline$v$ & Poisson's ratio of the retaining wall \\
\hline$v_{\mathrm{s}}$ & Velocity of the shear wave \\
\hline$v_{\mathrm{ur}}$ & Poisson's ratio of the soil for unloading-reloading conditions \\
\hline$W$ & Weight of the retaining wall \\
\hline$y$ & A constant, to account for the stress-level dependency of the stiffness of soil \\
\hline$z$ & Height of the wall measured above its base \\
\hline$\alpha, \beta$ & Rayleigh damping parameters \\
\hline$\Delta b_{\mathrm{w}}$ & Horizontal displacement at the base of the retaining wall \\
\hline$\Delta t_{\mathrm{w}}$ & Horizontal displacement at the top of the retaining wall \\
\hline$\Delta P$ & Seismic earth pressure force increment \\
\hline$\Delta P_{\mathrm{ae}}$ & Seismic active earth pressure force increment \\
\hline
\end{tabular}




\begin{tabular}{|c|c|}
\hline$\Delta P_{\mathrm{pe}}$ & Seismic passive earth pressure force increment \\
\hline$\gamma_{\mathrm{s}}$ & Unit weight of the soil \\
\hline$\gamma$ & Shear strain \\
\hline$\gamma_{0.7}$ & Reference shear strain, corresponding to $70 \%$ of $G_{o}^{r e f}$ \\
\hline$\gamma_{\mathrm{w}}$ & Unit weight of the retaining wall \\
\hline$\xi$ & Damping ratio \\
\hline$\theta$ & Rotation of the retaining wall about an axis passing through location $b_{\mathrm{w}}$ \\
\hline$\theta_{\text {active }}$ & Rotation of the retaining wall in the active direction \\
\hline$\theta_{\text {passive }}$ & Rotation of the retaining wall in the passive direction \\
\hline$\lambda_{\min }$ & Wavelength of the shear wave \\
\hline$\sigma_{3}^{\prime}$ & Effective confining pressure \\
\hline$\sigma_{\text {hei }}$ & Horizontal stress for each element \\
\hline$\sigma_{\text {ha,b }}$ & $\begin{array}{l}\text { Horizontal stress computed at the Gauss integration points a and } \mathrm{b} \text { which are } \\
\text { in contact with the retaining wall }\end{array}$ \\
\hline$\phi^{\prime}$ & Effective friction angle of the soil \\
\hline$\psi$ & Dilatancy of the soil \\
\hline
\end{tabular}

Abbreviations

2D

Two-dimensional

CG Centre of gravity of the retaining wall

FE Finite element

HSsmall Hardening soil with small strain model

MO Mononobe-Okabe theory

PGA Peak ground acceleration 


\section{References}

[1] Coulomb, C.A. Essais sur une application des regles des maximis et minimis a quelques problems de statique relatits a l'architecture. Mem Acad Roy Pres Divers Sav. 1776; 7:343382.

[2] Rankine, W.J.M. On the stability of loose earth. Philos. Trans. R. Soc. London. 1857; 147:9-27.

[3] Bang, S., Hwang, S. Transition of active lateral earth pressures behind retaining walls. Comput Geotech. 1986; 2(4):219-238.

[4] Peng, S.-q., Li, X.-b., Fan, L., Liu, A.-h. A general method to calculate passive earth pressure on rigid retaining wall for all displacement modes. Transactions of Nonferrous Metals Society of China. 2012; 22(6):1526-1532.

[5] Liu, F. Lateral earth pressures acting on circular retaining walls. Int J Geomech. 2013; 14(3): 04014002

[6] Fang, Y., Ishibashi, I. Static earth pressures with various wall movements. J Geotech Eng -ASCE. 1986; 112(3):317-333.

[7] Fang, Y., Chen, T., Wu, B. Passive earth pressures with various wall movements. J Geotech Eng -ASCE. 1994; 120(8):1307-1323.

[8] Bhatia, S.K., Bakeer, R.M. Use of the finite element method in modelling a static earth pressure problem. Int J Numer Anal Met Geomech.. 1989; 13(2):207-213.

[9] Addenbrooke, T., Potts, D., Dabee, B. Displacement flexibility number for multipropped retaining wall design. J Geotech Geoenviron Eng ASCE. 2000. 2000; 126(8):718-726.

[10] Fan, C.-C., Fang, Y.-S. Numerical solution of active earth pressures on rigid retaining walls built near rock faces. Comput Geotech. 2010; 37(7):1023-1029.

[11] Achmus, M. Numerical modeling of three-dimensional active earth pressure acting on rigid walls. Comput Geotech. 2013; 51:83-90.

[12] Okabe, S. General theory of earth pressure. J Jpn Soc Civil Eng. 1926; 12(1):311.

[13] Mononobe, N., Matsuo, H. On the determination of earth pressures during earthquakes. In Proceedings, World Engineering Congress. 9; 1929. 179-187.

[14] Wood, J.H. Earthquake induced soil pressures on structures. $\mathrm{PhD}$ Thesis, California Institute of Technology, Pasadena, CA. 1973.

[15] Steedman, R., Zeng, X. The influence of phase on the calculation of pseudo-static earth pressure on a retaining wall. Geotechnique. 1990; 40(1):103-112.

[16] Ortigosa, P. Seismic earth pressure including soil cohesion. In Proceeding of 16th international conference on soil mechanics and geotechnical engineering, Osaka. 2005.

[17] Mylonakis, G., Kloukinas, P., Papantonopoulos, C. An alternative to the MononobeOkabe equations for seismic earth pressures. Soil Dyn Earthq Eng. 2007; 27(10):957-969.

[18] Evangelista, A., Scotto di Santolo, A., Simonelli, A.L. Evaluation of pseudostatic active earth pressure coefficient of cantilever retaining walls. Soil Dyn Earthq Eng. 2010; 30(11):1119-1128.

[19] Choudhury, D., Nimbalkar, S. Seismic passive resistance by pseudo-dynamic method. Geotechnique. 2005; 55, 699-702.

[20] Choudhury, D., Nimbalkar, S. S. Pseudo-dynamic approach of seismic active earth pressure behind retaining wall. Geotechnical and geological engineering. 2006; 24, 1103-1113.

[21] Al Atik, L.,Sitar, N. Experimental and analytical study of the seismic performance of retaining structures. PEER Report 2008/104, Pacific Earthquake Engineering Research Center, College of Engineering, University of California, Berkeley. 2008. 
[22] Wilson, P.,Elgamal, A. Shake table lateral earth pressure testing with dense c- $\square$ backfill. Soil Dyn Earthq Eng. 2015; 71:13-26.

[23] Candia, G., Mikola, R.G., Sitar, N. Seismic response of retaining walls with cohesive backfill: Centrifuge model studies. Soil Dyn Earthq Eng. 2016; 90:411-419.

[24] Ertugrul, O.L., Trandafir, A.C., Yener Ozkan, M. Reduction of dynamic earth loads on flexible cantilever retaining walls by deformable geofoam panels. Soil Dyn Earthq Eng. 2017; 92:462-471.

[25] Athanasopoulos -Zekkos, A., Vlachakis, V. S. \& Athanasopoulos, G. A. Phasing issues in the seismic response of yielding, gravity-type earth retaining walls - Overview and results from a FEM study. Soil Dyn Earthq Eng. 2013; 55, 59-70.

[26] Kitsis, V., Vlachakis, V., Athanasopoulos, G., Athanasopoulos-Zekkos, A. Seismic Thrust vs. Wall Inertia in Non-Yielding Retaining Walls under Earthquake Loading: Synchronous or Asynchronous Action? IFCEE. 2015; 1513-1521.

[27] Wu, Y.,Prakash, S. Seismic displacements of rigid retaining walls on submergence. In Proceeding of 12th World Conference on Earthquake Engineering. Auckland: IAEE. 570; 2000.

[28] Richards, R., Elms DG. Seismic behaviour of gravity retaining walls. J Geot. Engrg. Dn., ASCE. 1979;105(4)449-64.

[29] Newmark. Effect of earthquakes on dams and embankments. Geotechnique 1965; 15:139159.

[30] Caltabiano, S., Cascone, E., Maugeri, M. Seismic stability of retaining walls with surcharge. Soil Dyn Earthq Eng. 2000; 20(5-8):469-476.

[31] Stamatopoulos CA, Velgaki EG, Modaressi A, F, L.-C. Seismic displacement of gravity walls by a two body model. Bull Earthq Eng. 2006; 4:295-318.

[32] Nimbalkar, S.,Choudhury, D. Sliding stability and seismic design of retaining wall by pseudo-dynamic method for passive case. Soil Dyn Earthq Eng. 2007; 27(6):497-505.

[33] Alyami, M., Rouainia, M., Wilkinson, S.M. Numerical analysis of deformation behaviour of quay walls under earthquake loading. Soil Dyn Earthq Eng. 2009; 29(3):525-536.

[34] Basha, B.M.,Babu, G.L.S. Computation of sliding displacements of bridge abutments by pseudo-dynamic method. Soil Dyn Earthq Eng. 2009; 29(1):103-120.

[35] Trandafir, A.C., Kamai, T., Sidle, R.C. Earthquake-induced displacements of gravity retaining walls and anchor-reinforced slopes. Soil Dyn Earthq Eng. 2009; 29(3):428-437.

[36] Jamshidi, R., Towhata, I., Ghiassian, H., Tabarsa, A.R. Experimental evaluation of dynamic deformation characteristics of sheet pile retaining walls with fiber reinforced backfill. Soil Dyn Earthq Eng. 2010; 30(6):438-446.

[37] Li, X., Wu, Y., He, S. Seismic stability analysis of gravity retaining walls. Soil Dyn Earthq Eng. 2010; 30(10):875-878.

[38] Tiznado, J.C.,Rodríguez-Roa, F. Seismic lateral movement prediction for gravity retaining walls on granular soils. Soil Dyn Earthq Eng. 2011; 31(3):391-400.

[39] Conti, R., Viggiani, G.M.B., Cavallo, S. A two-rigid block model for sliding gravity retaining walls. Soil Dyn Earthq Eng. 2013; 55(0):33-43.

[40] Vlachakis, V., Athanasopoulos, G., Athanasopoulos-Zekkos, A. Seismic Displacements of Yielding Gravity-Type Earth-Retaining Walls-Results from a FEM study. Geo-Congress 2014: Geo-characterization and Modeling for Sustainability, 2014; 3188-3197.

[41] Pain, A., Choudhury, D., Bhattacharyya, S. K. Seismic rotational stability of gravity retaining walls by modified pseudo-dynamic method. Soil Dyn Earthq Eng. 2017; 94, 244253.

[42] Veletsos, A.,Younan, A. Dynamic response of cantilever retaining walls. J Geotech Geoenviron Eng ASCE. 1997; 123(2):161-172.

[43] Zhang, J., Shamoto, Y., Tokimatsu, K. Seismic earth pressure theory for retaining walls under any lateral displacement. Soils Found. 1998; 38(2):143-163. 
[44] Richards, J., R., Huang, C., Fishman, K. Seismic earth pressure on retaining structures. J Geotech Geoenviron Eng ASCE. 1999; 125(9):771-778.

[45] Ishibashi, I.,Fang, Y.-S. Dynamic earth pressures with different wall movement modes. Soils Found. 1987; 27(4):11-22.

[46] Gazetas, G., Psarropoulos, P.N., Anastasopoulos, I., Gerolymos, N. Seismic behaviour of flexible retaining systems subjected to short-duration moderately strong excitation. Soil Dyn Earthq Eng. 2004; 24(7):537-550.

[47] Giarlelis, C.,Mylonakis, G. Interpretation of dynamic retaining wall model tests in light of elastic and plastic solutions. Soil Dyn Earthq Eng. 2011; 31(1):16-24.

[48] Nakamura, S. Reexamination of Mononobe-Okabe theory of gravity retaining walls using centrifuge model tests. Soils Found. 2006; 46(2):135-146.

[49] PLAXIS2D. Reference manual,. 2015; Last version 2015.2.19890.4979.

[50] Okamura, M.,Matsuo, O. A displacement prediction method for retaining walls under seismic loading. Soils and Foundations 2002; 42(1):131-138.

[51] Kuhlemeyer, R.L.,Lysmer, J. Finite element method accuracy for wave propagation problems. J Soil Mech Found Div. 1973; 99:421-7.

[52] Hardin, B.,Drnevich, V. Shear modulus and damping in soils: Design equations and curves. J Soil Mech Found Div. 1972; 98:667-692.

[53] Rajasekaran, S. Structural dynamics of earthquake engineering: Theory and application using Mathematica and Matlab: Woodhead Publishing2009: Woodhead Publishing.

[54] Systèmes, D. Abaqus manual version 6.13.2013.

[55] Benz, T. Small-strain stiffness of soils and its numerical consequences: Univ. Stuttgart, Inst. f. Geotechnik2007: Univ. Stuttgart, Inst. f. Geotechnik.

[56] Griffiths, S.C., Cox, B.R., Rathje, E.M. Challenges associated with site response analyses for soft soils subjected to high-intensity input ground motions. Soil Dyn Earthq Eng. 2016; $85: 1-10$.

[57] Stamati, O., Klimis, N., Lazaridis, T. Evidence of complex site effects and soil nonlinearity numerically estimated by $2 \mathrm{~d}$ vs $1 \mathrm{~d}$ seismic response analyses in the city of xanthi. Soil Dyn Earthq Eng. 2016; 87:101-115. 


\section{Figure captions}

Fig. 1: Cross-section of a typical soil-retaining wall system.

Fig. 2: FE model of the soil-retaining wall system.

Fig. 3: Stress-strain relationship from a typical soil strength test.

Fig. 4: (a) Shear modulus variation with shear strain, (b) Example of the generation of hysteretic damping with shear strain [49].

Fig. 5: Loma Prieta 1989 earthquake acceleration-time history.

Fig. 6: Cross-section for the (a) Saito et al. (see [50]) and (b) Nakamura [48] centrifuge tests.

Fig. 7: Seismic input motion used in the present study and applied at the base of the (a) Saito et al. (see [50]), and (b, c, d) Nakamura [48] centrifuge tests.

Fig. 8: FE models developed for the (a) Saito et al. (see [50]), and (b) Nakamura [48] centrifuge tests.

Fig. 9: Horizontal displacement predictions from the FE model at the (a) base of the retaining wall and comparison with the Saito et al. centrifuge test (see [50]), and (b) top of the retaining wall and comparison with the Nakamura centrifuge test [48].

Fig. 10: Present study FE predictions and comparison with the Nakamura centrifuge test [48] for the seismic (a) active, and (b) passive earth pressure distributions.

Fig. 11: Seismic earth pressure force increment predictions for the (a) Nakamura centrifuge test [48], and (b) Present study FE model.

Fig. 12: Displacement, acceleration, horizontal seismic inertia force, and seismic earth pressure force directions for the active and passive cases. 
Fig. 13: Acceleration-time history predictions at various locations of the FE model.

Fig. 14: Horizontal displacement at the (a) centre of gravity of the retaining wall, (b) top of the retaining wall, (c) top of the backfill soil, and (d) reference point in the foundation soil, located 0.5 $\mathrm{m}$ below the base of the retaining wall.

Fig. 15: Relative horizontal displacement between (a) top of the retaining wall and a reference point in the foundation soil, located $0.5 \mathrm{~m}$ below the base of the retaining wall, representing sliding and/or permanent displacement, and (b) top of the retaining wall and top of the backfill soil.

Fig. 16: Rotation of the retaining wall.

Fig. 17: Horizontal seismic inertia force of the retaining wall.

Fig. 18: Seismic earth pressure force (a) as obtained from the FE model, and (b) a simplified version.

Fig. 19: (a) Static active earth pressure at $t=0 \mathrm{~s}$, (b) Seismic active earth pressure at $t=3.8 \mathrm{~s}$, (c) Seismic passive earth pressure at $t=4.5 \mathrm{~s}$, and (d) Seismic residual earth pressure at $t=30 \mathrm{~s}$.

Fig. 20: Horizontal seismic inertia force of the retaining wall and seismic earth pressure force increment.

Fig. 21: Unique design chart for different retaining wall heights showing a relationship between: (a) seismic earth pressure force and horizontal displacement at the top of the retaining wall, (b) maximum permanent displacement of the retaining wall and amplitude of the seismic input motion.

Fig. 22: Unique design chart for different frequency content and amplitude of seismic input motion showing a relationship between: (a) normalised seismic earth pressure force and horizontal 
displacement at the top of the retaining wall, (b) maximum permanent displacement of the retaining wall and amplitude of the seismic input motion.

Fig. A.1: Convergence analysis results to decide the minimum size of the elements for the FE model. 


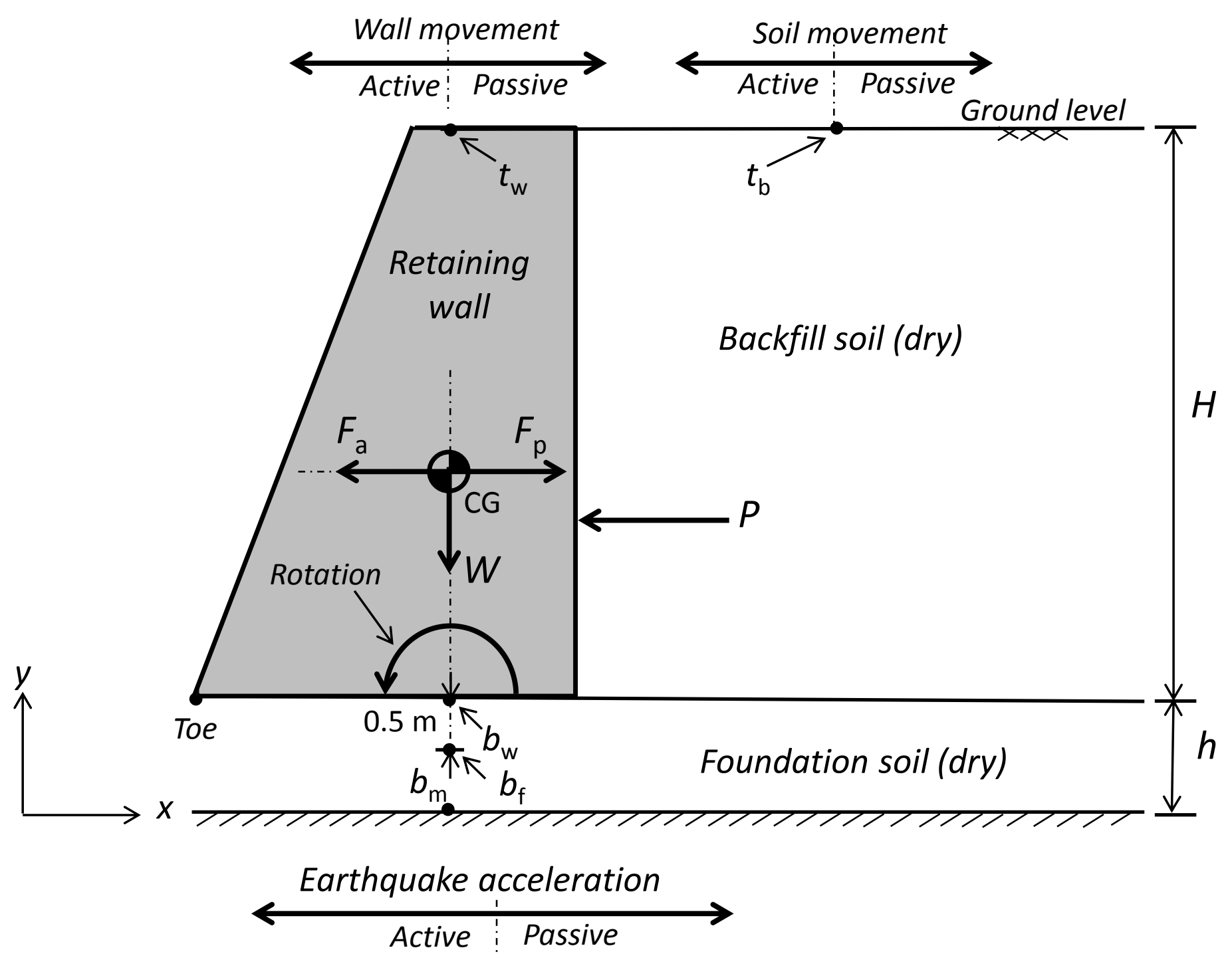

Fig. 1: Cross-section of a typical soil-retaining wall system. 


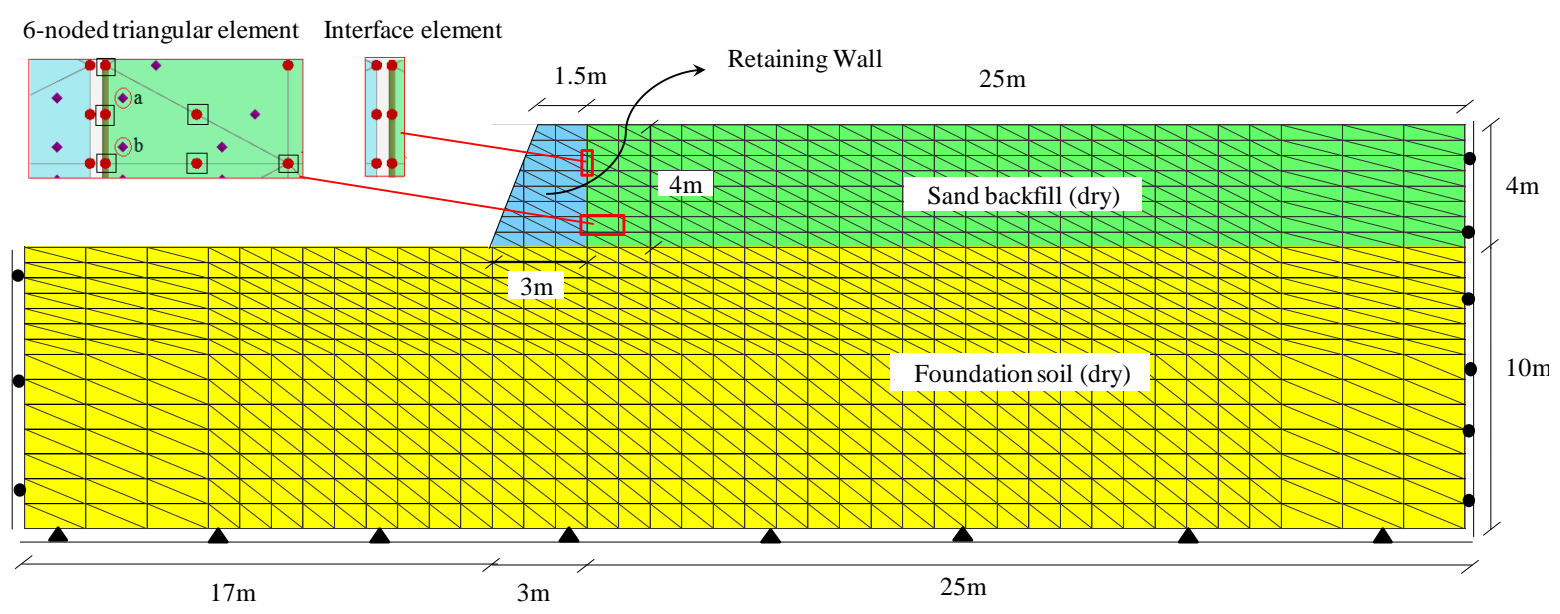

Fig. 2: FE model of the soil-retaining wall system. 


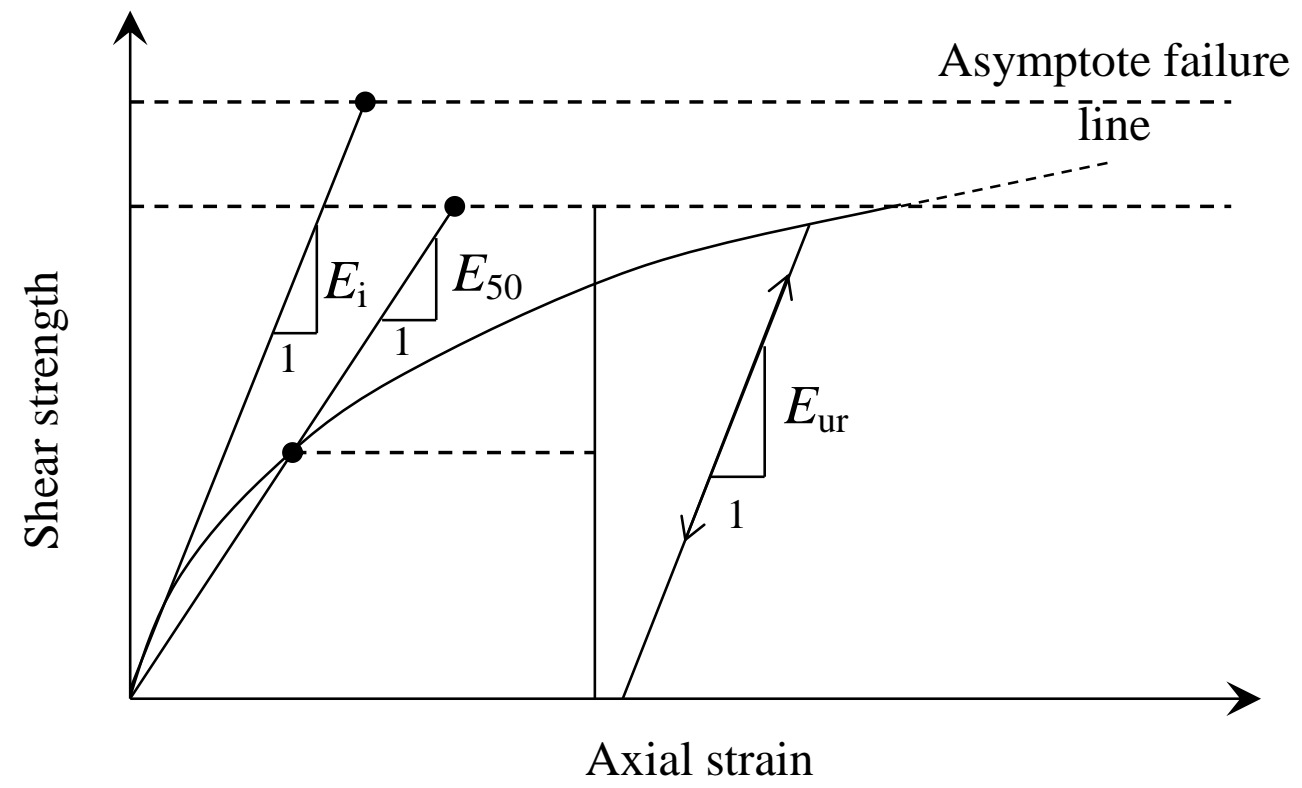

Fig. 3: Stress-strain relationship from a typical soil strength test. 


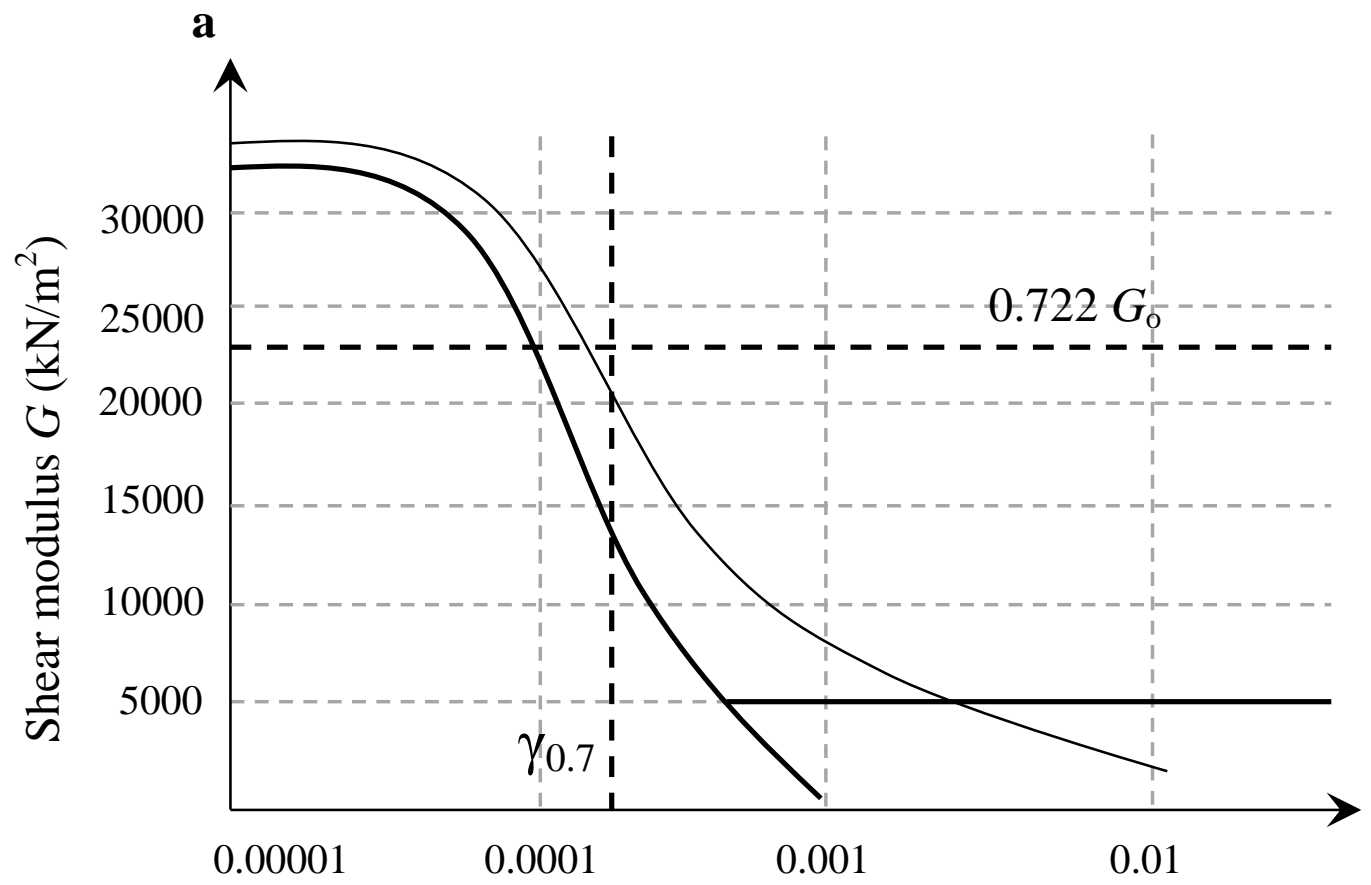

Shear strain $\gamma$

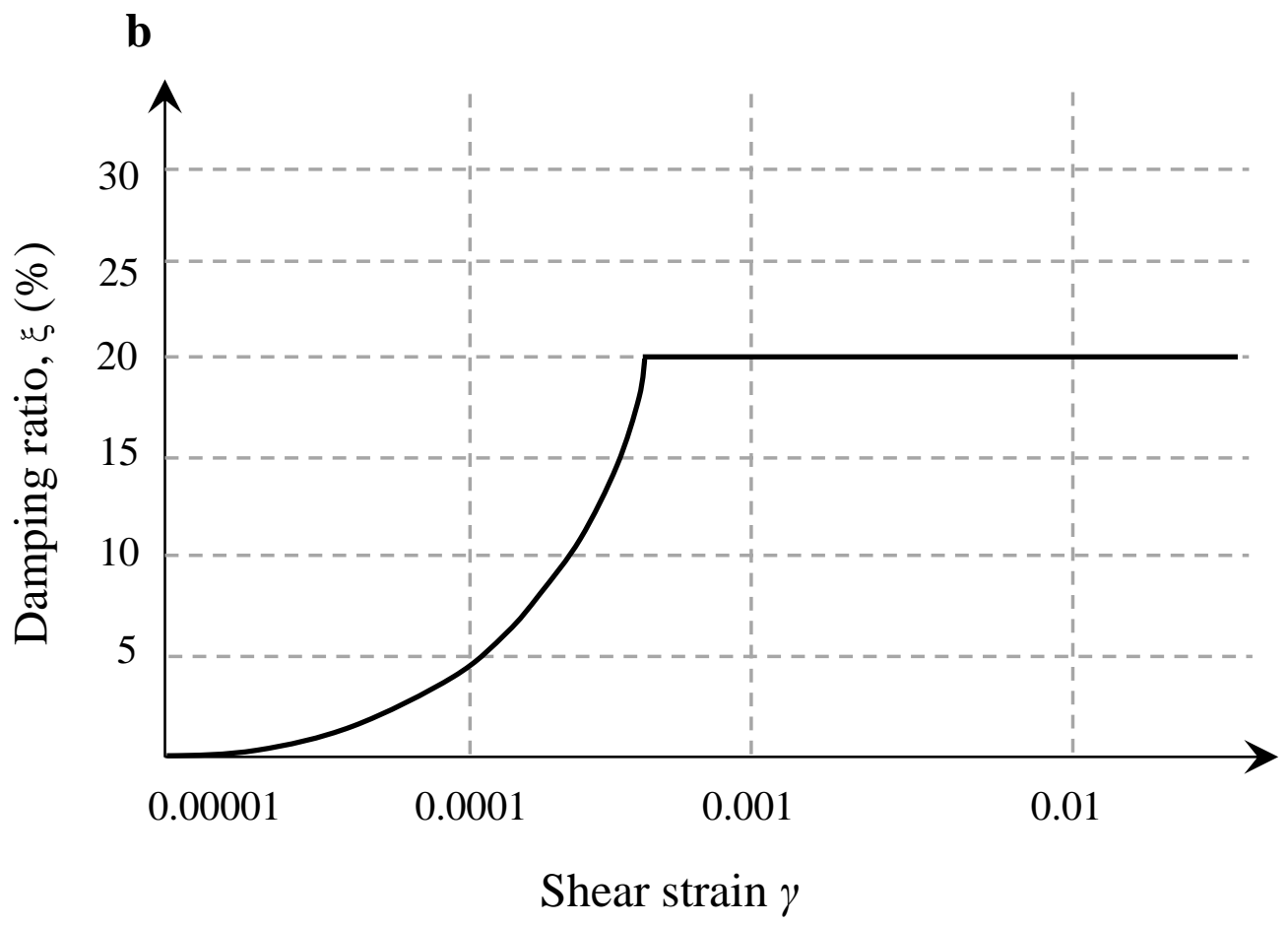

Fig. 4: (a) Shear modulus variation with shear strain, (b) Example of the generation of hysteretic damping with shear strain [49]. 


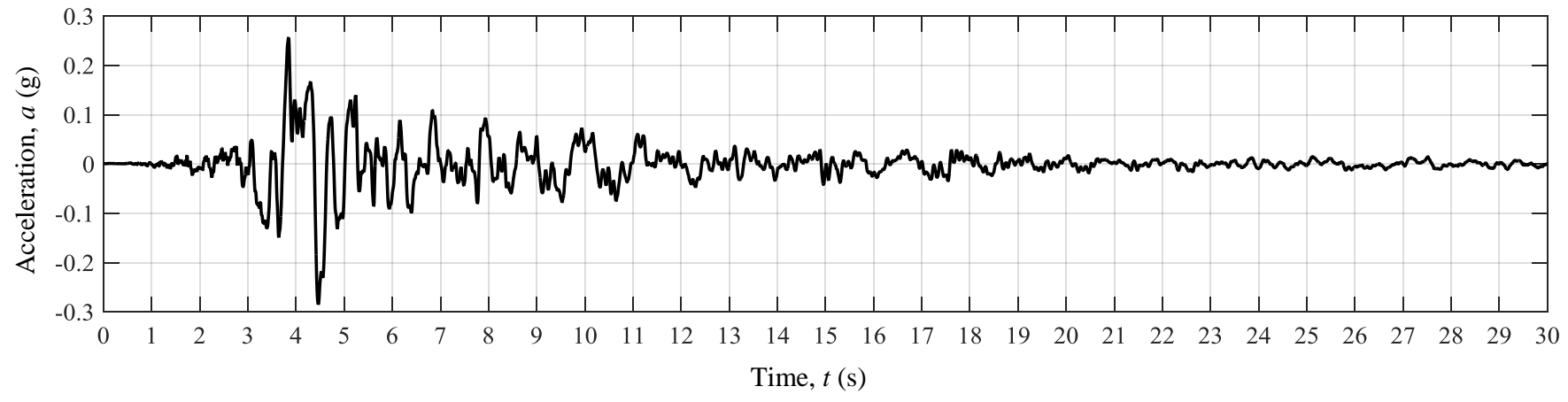

Fig. 5: Loma Prieta 1989 earthquake acceleration-time history. 
$\mathbf{a}$

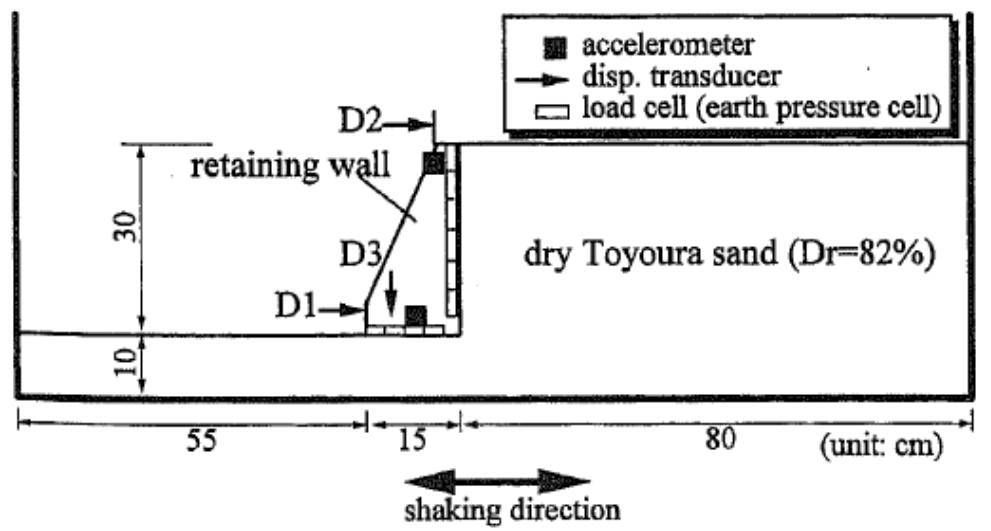

b

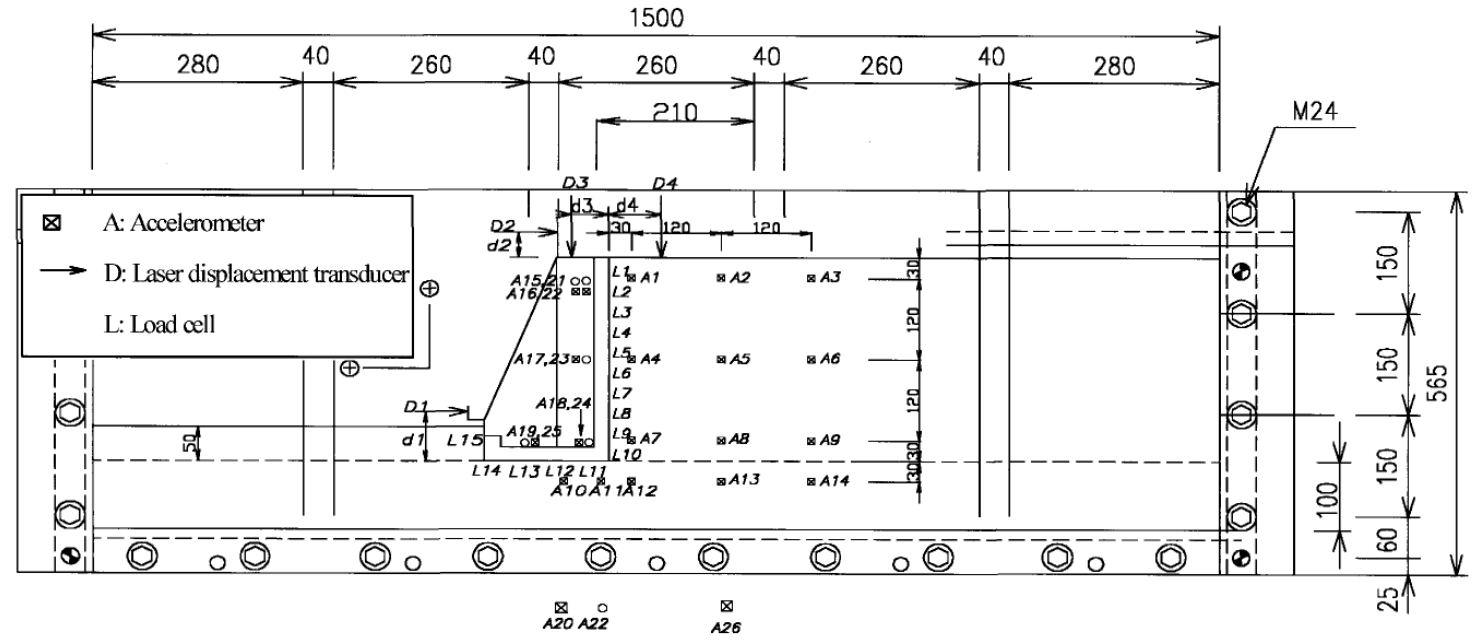

Fig. 6: Cross-section for the (a) Saito et al. (see [50]) and (b) Nakamura [48] centrifuge tests. 
$\mathbf{a}$
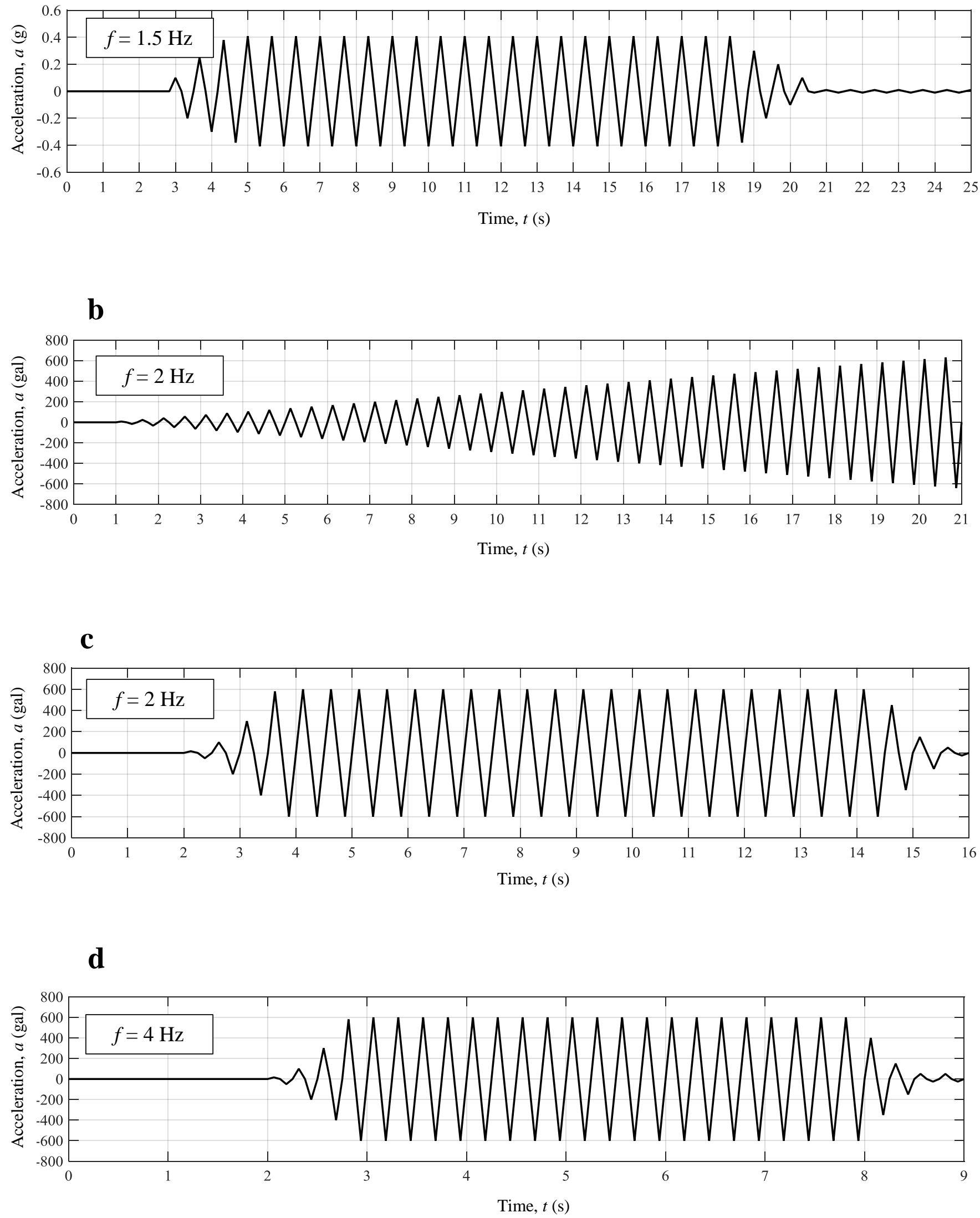

Fig. 7: Seismic input motion used in the present study and applied at the base of the (a) Saito et al. (see [50]), and (b, c, d) Nakamura [48] centrifuge tests. 

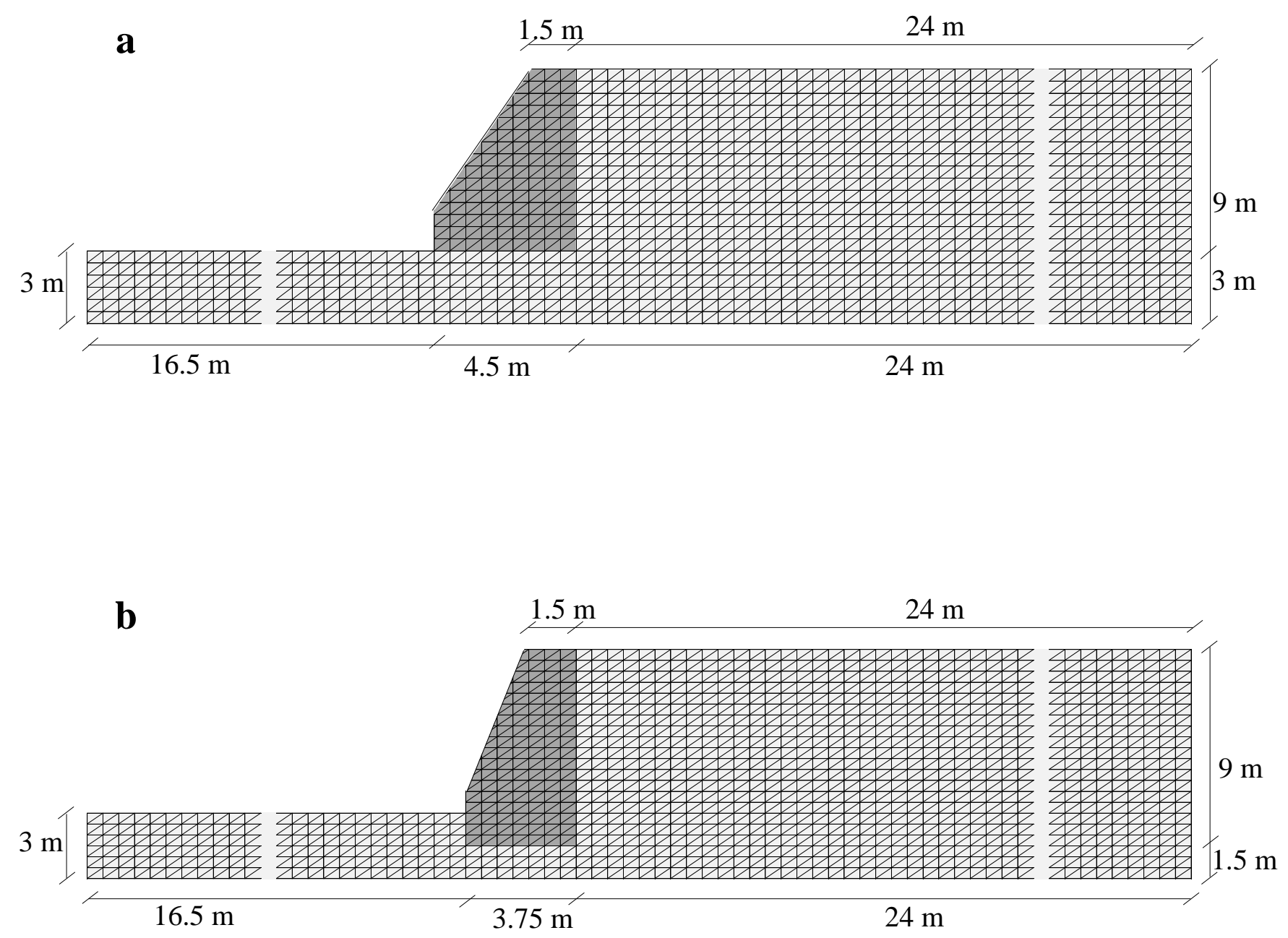

Fig. 8: FE models developed for the (a) Saito et al. (see [50]), and (b) Nakamura [48] centrifuge tests. 
$\mathbf{a}$

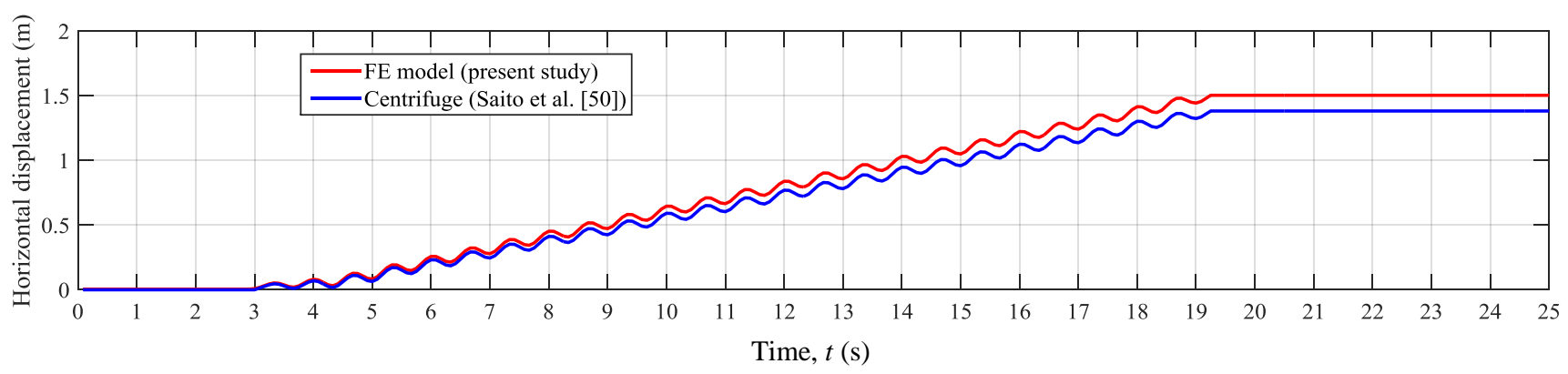

b

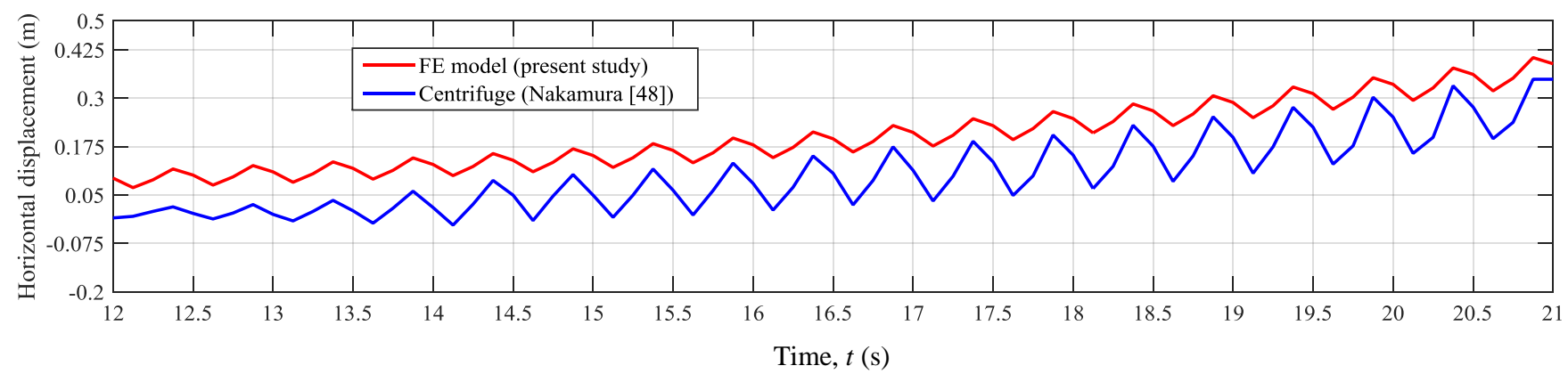

Fig. 9: Horizontal displacement predictions from the FE model at the (a) base of the retaining wall and comparison with the Saito et al. centrifuge test (see [50]), and (b) top of the retaining wall and comparison with the Nakamura centrifuge test [48]. 


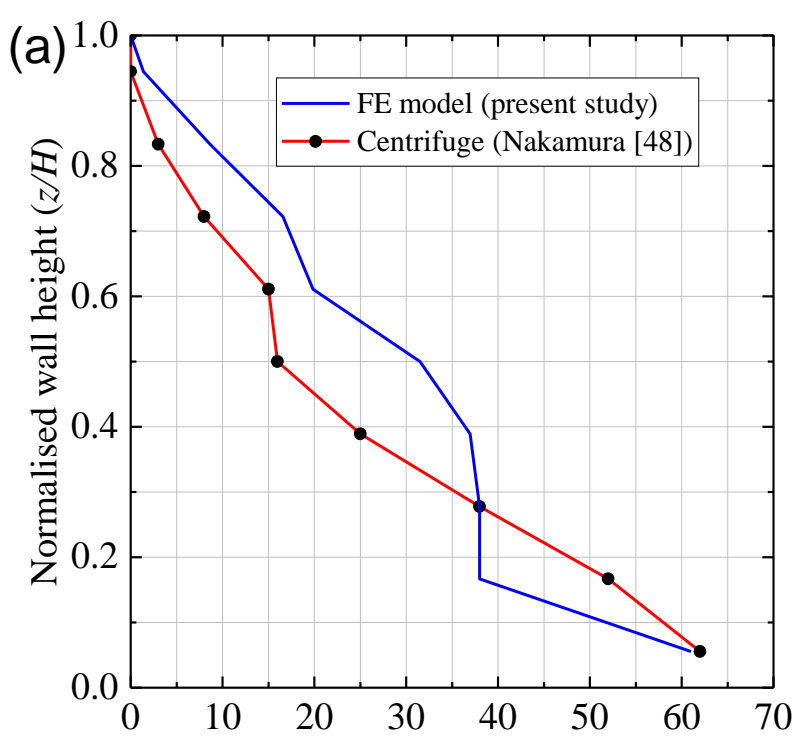

Seismic active earth pressure $\left(\mathrm{kN} / \mathrm{m}^{2}\right)$ $[t=8.34 \mathrm{~s}]$

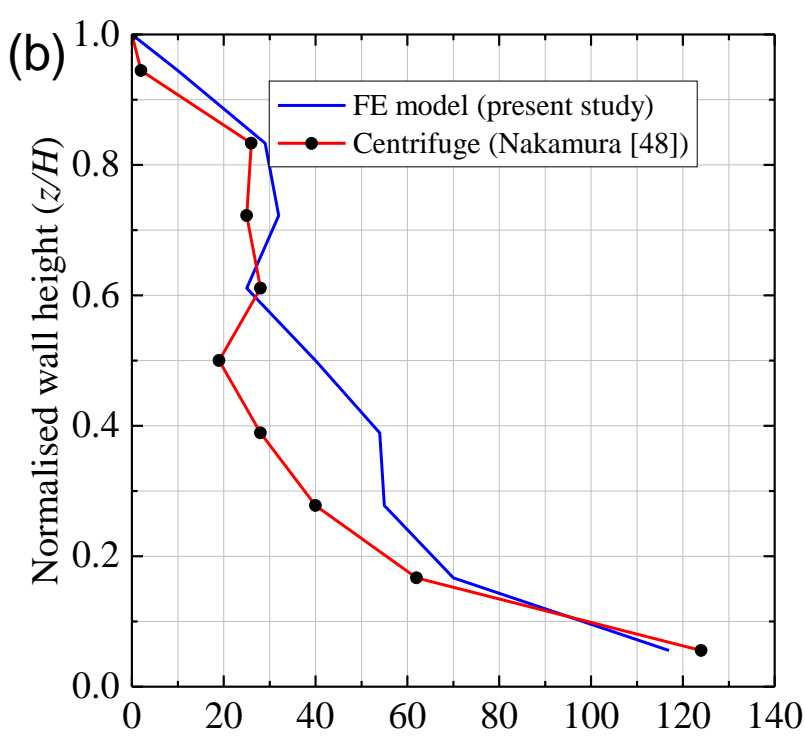

Seismic passive earth pressure $\left(\mathrm{kN} / \mathrm{m}^{2}\right)$ $[t=8.58 \mathrm{~s}]$

Fig. 10: Present study FE predictions and comparison with the Nakamura centrifuge test [48] for the seismic (a) active, and (b) passive earth pressure distributions. 

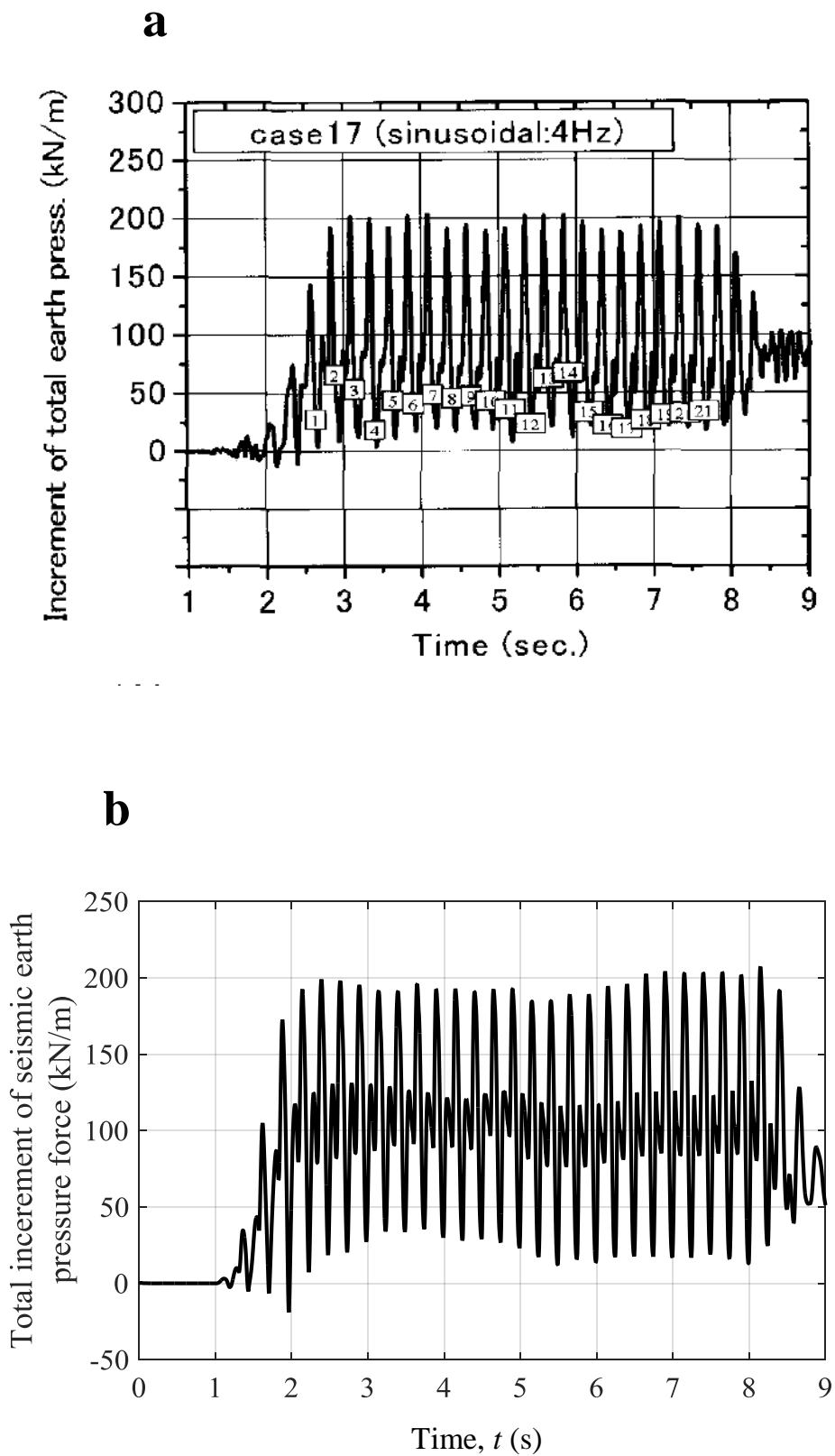

Fig. 11: Seismic earth pressure force increment predictions for the (a) Nakamura centrifuge test [48], and (b) Present study FE model. 


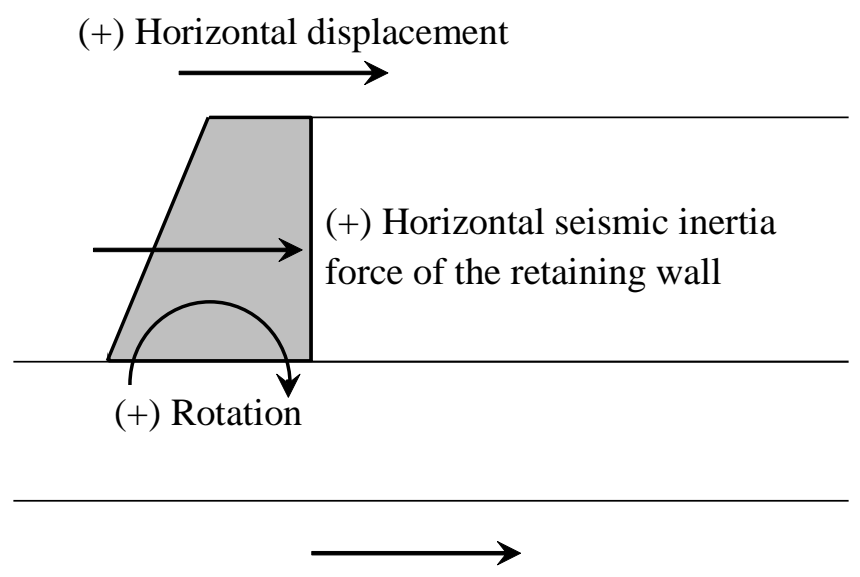

(+) Acceleration

Fig. 12: Displacement, acceleration, horizontal seismic inertia force, and seismic earth pressure force directions for the active and passive cases. 


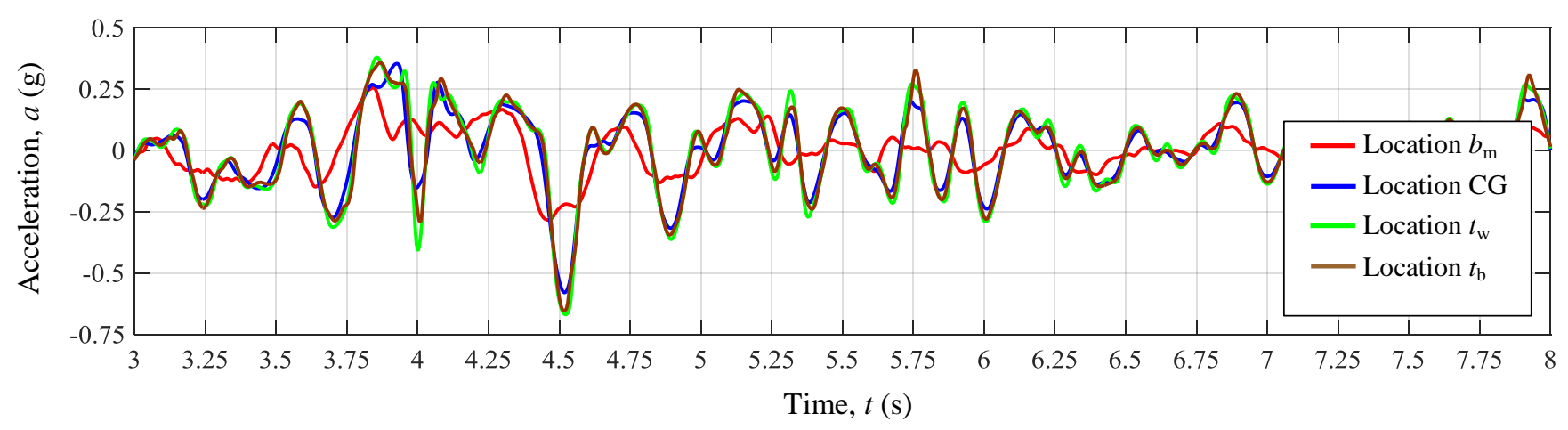

Fig. 13: Acceleration-time history predictions at various locations of the FE model. 

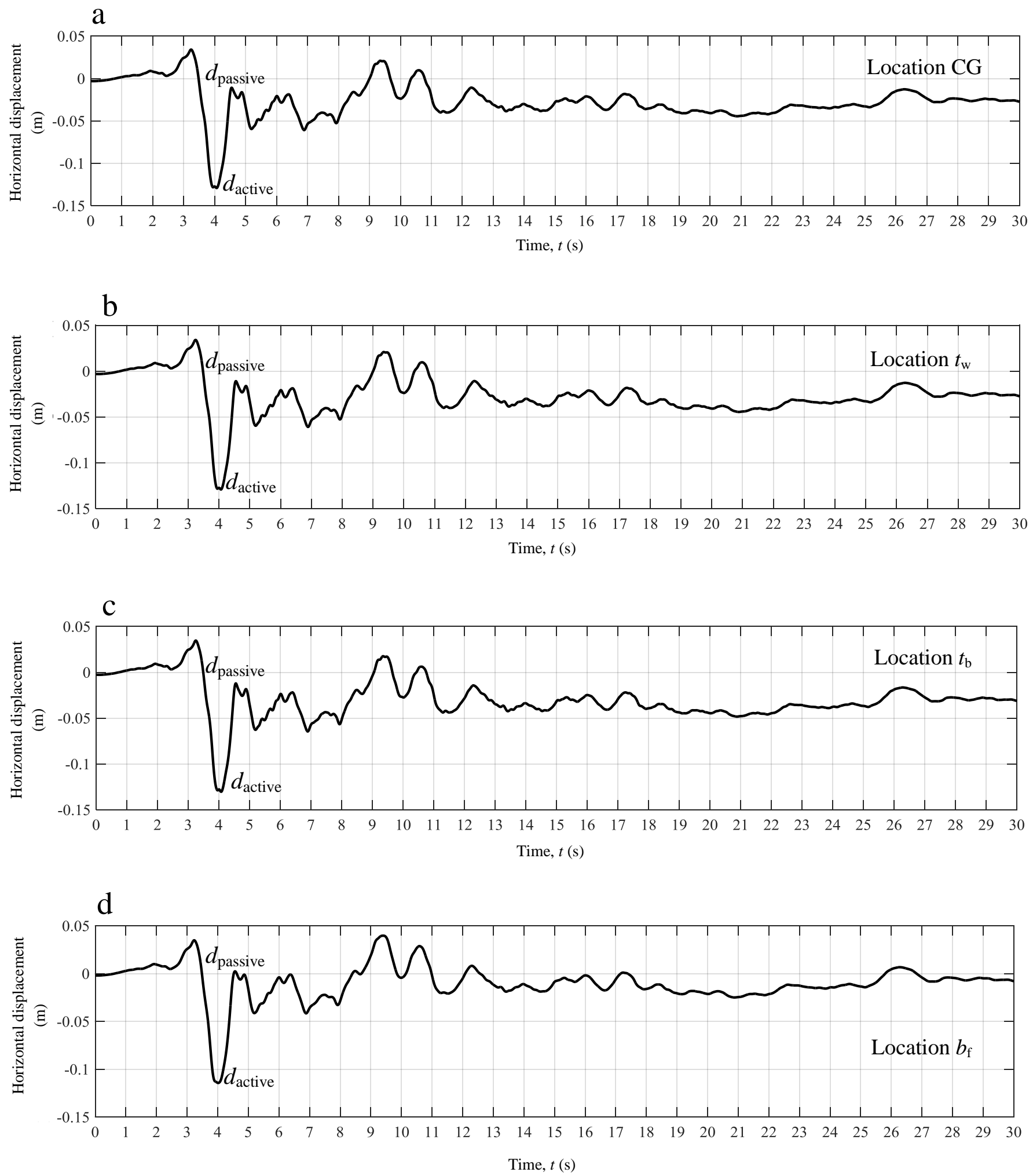

Fig. 14: Horizontal displacement at the (a) centre of gravity of the retaining wall, (b) top of the retaining wall, (c) top of the backfill soil, and (d) reference point in the foundation soil, located $0.5 \mathrm{~m}$ below the base of the retaining wall. 


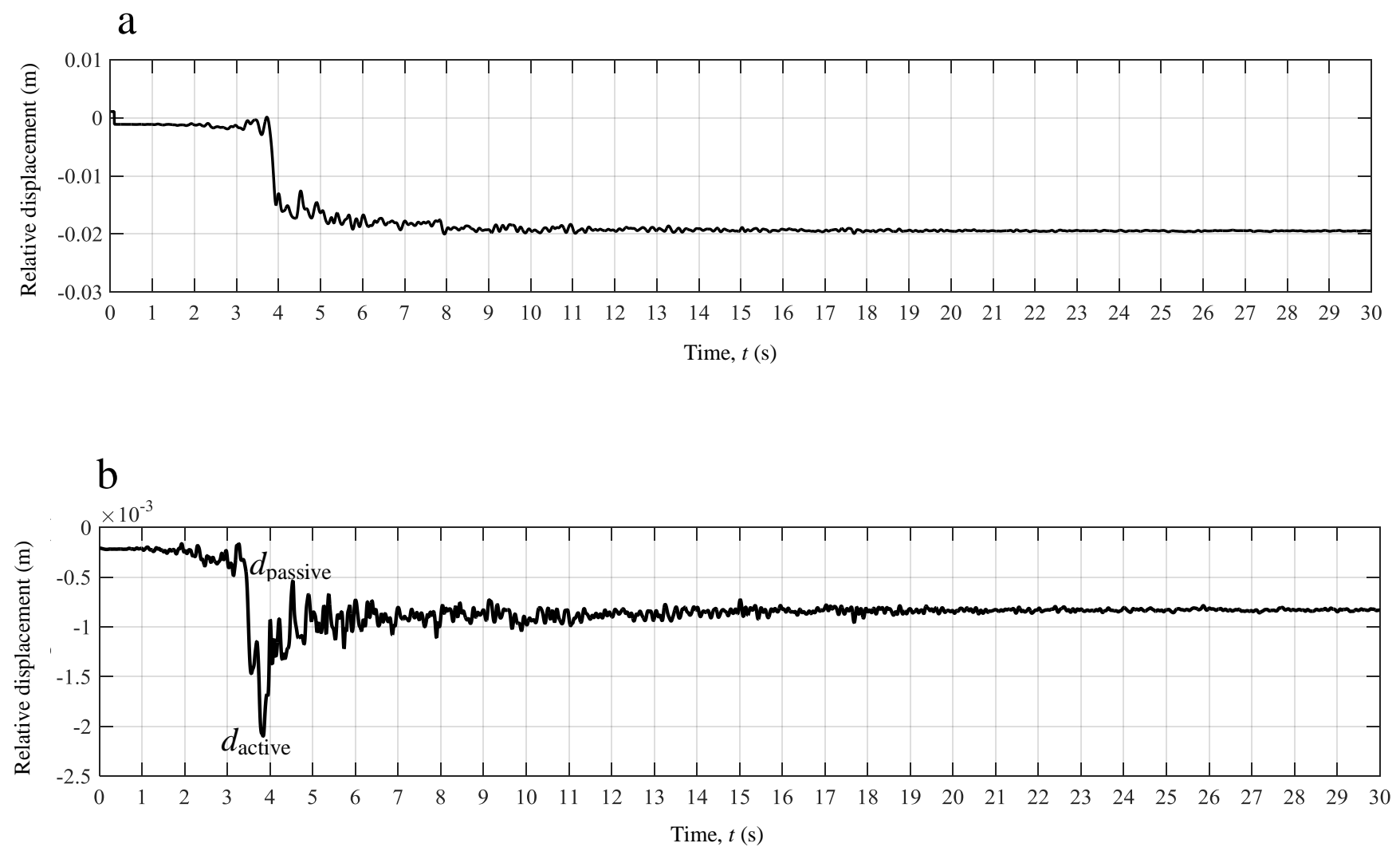

Fig. 15: Relative horizontal displacement between (a) top of the retaining wall and a reference point in the foundation soil, located $0.5 \mathrm{~m}$ below the base of the retaining wall, representing sliding and/or permanent displacement, and (b) top of the retaining wall and top of the backfill soil. 


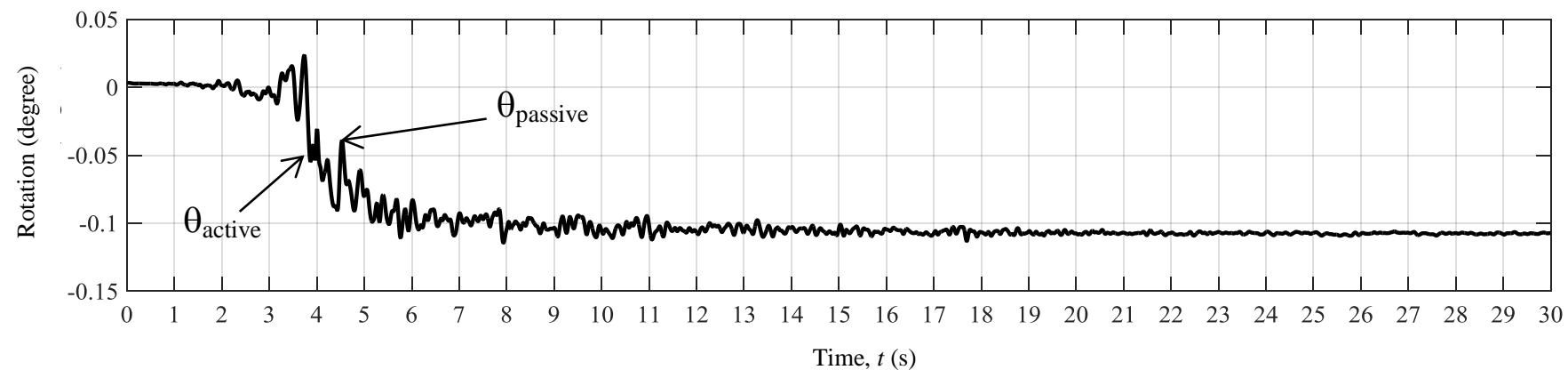

Fig. 16: Rotation of the retaining wall. 


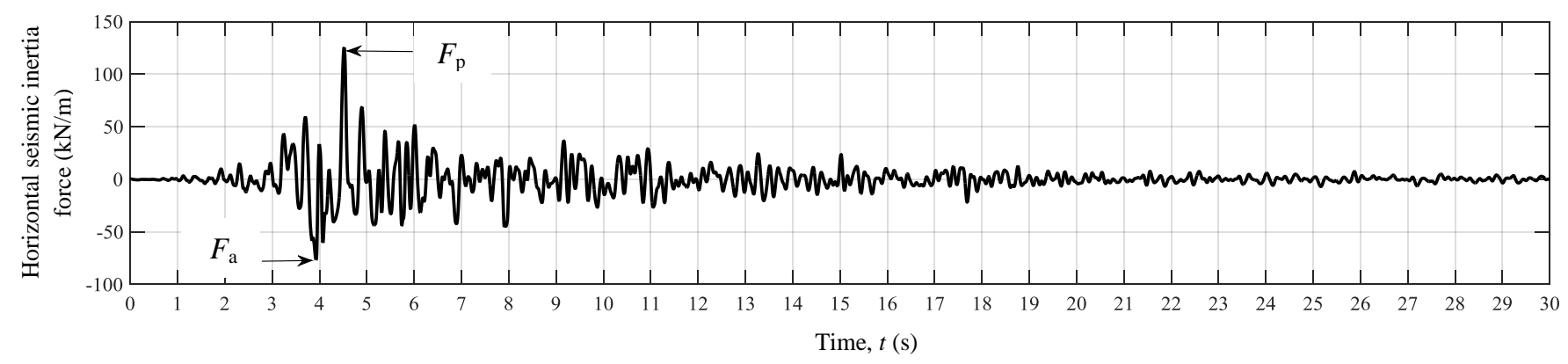

Fig. 17: Horizontal seismic inertia force of the retaining wall. 


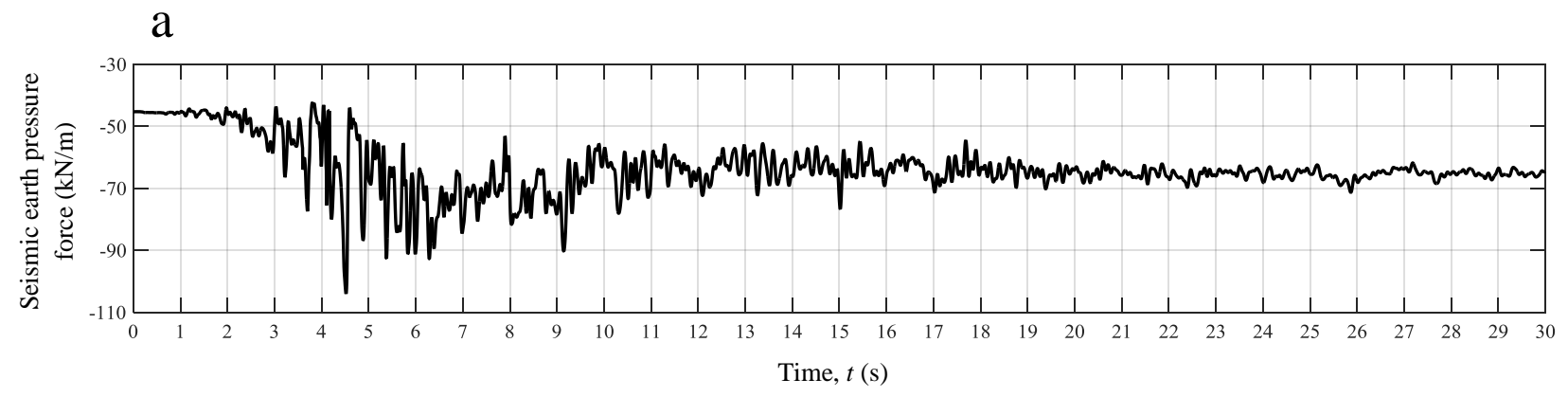

b

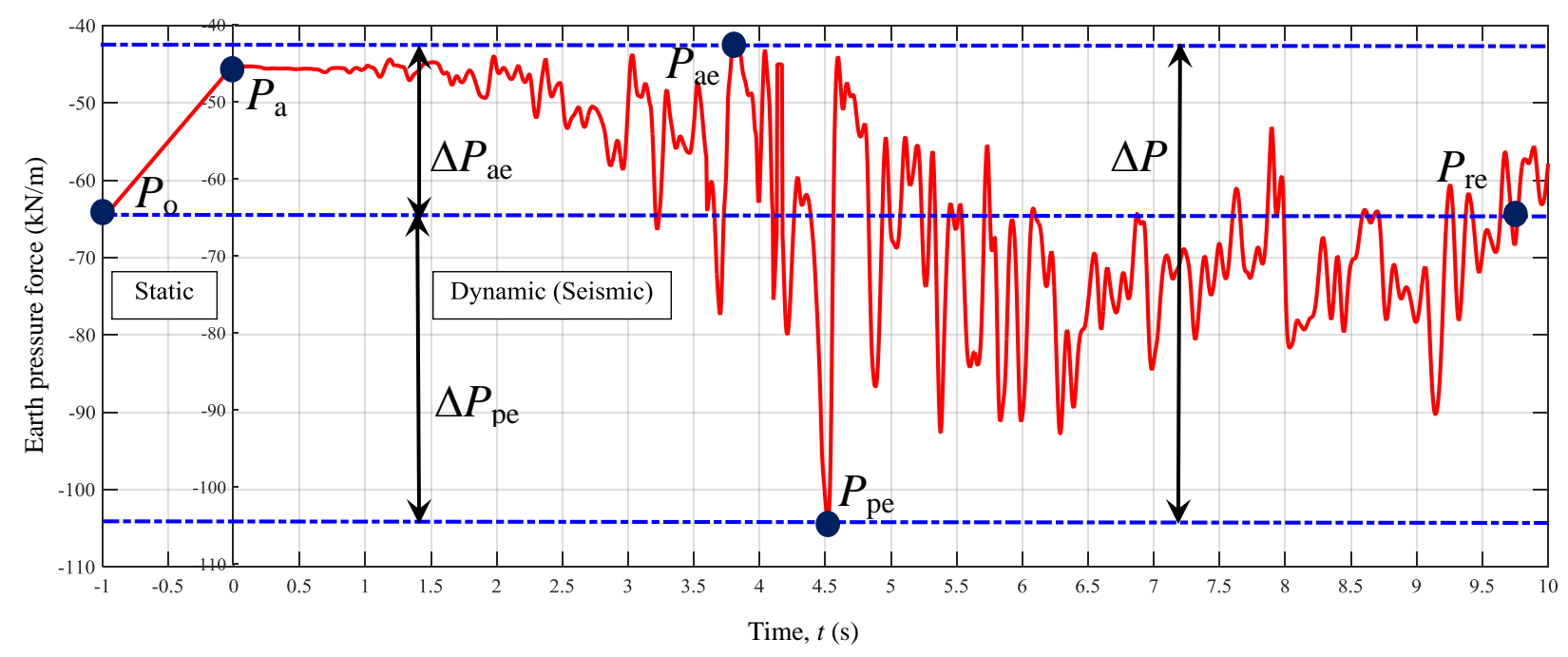

Fig. 18: Seismic earth pressure force (a) as obtained from the FE model, and (b) a simplified version. 

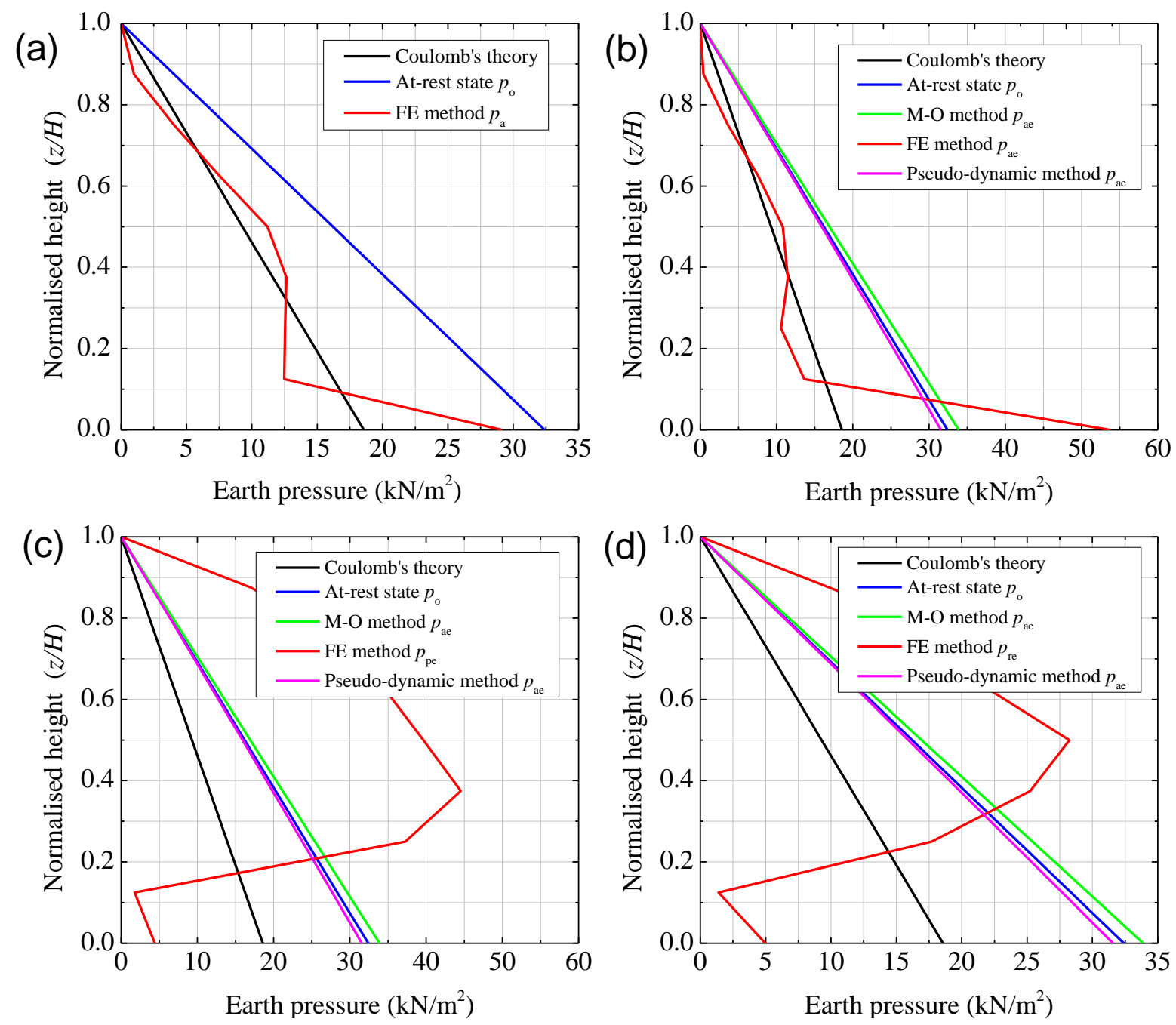

Fig. 19: (a) Static active earth pressure at $t=0 \mathrm{~s}$, (b) Seismic active earth pressure at $t=3.8 \mathrm{~s}$, (c) Seismic passive earth pressure at $t=4.5 \mathrm{~s}$, and (d) Seismic residual earth pressure at $t=30 \mathrm{~s}$. 


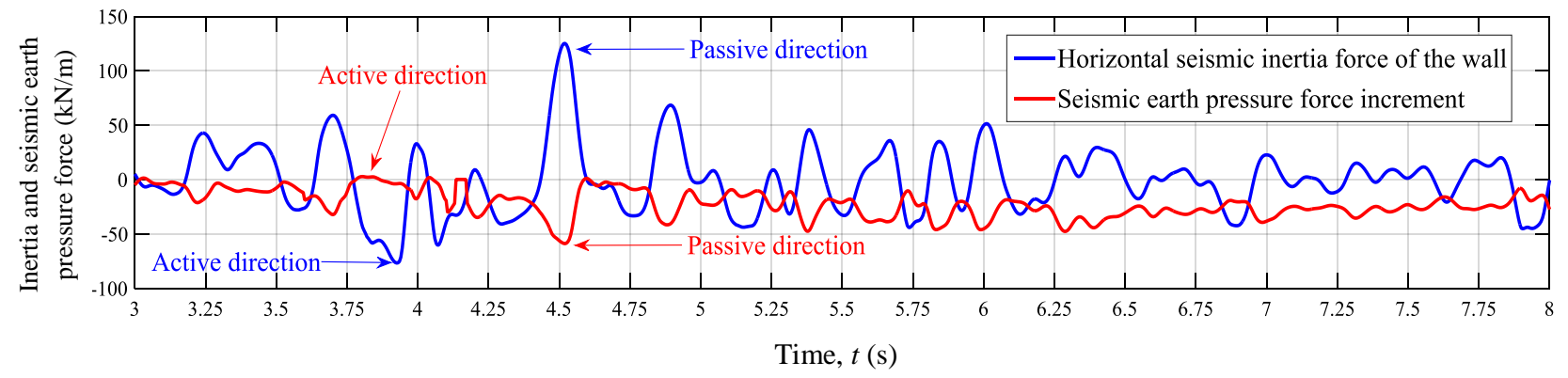

Fig. 20: Horizontal seismic inertia force of the retaining wall and seismic earth pressure force increment. 
$\mathbf{a}$

Acceleration, $a(g)$

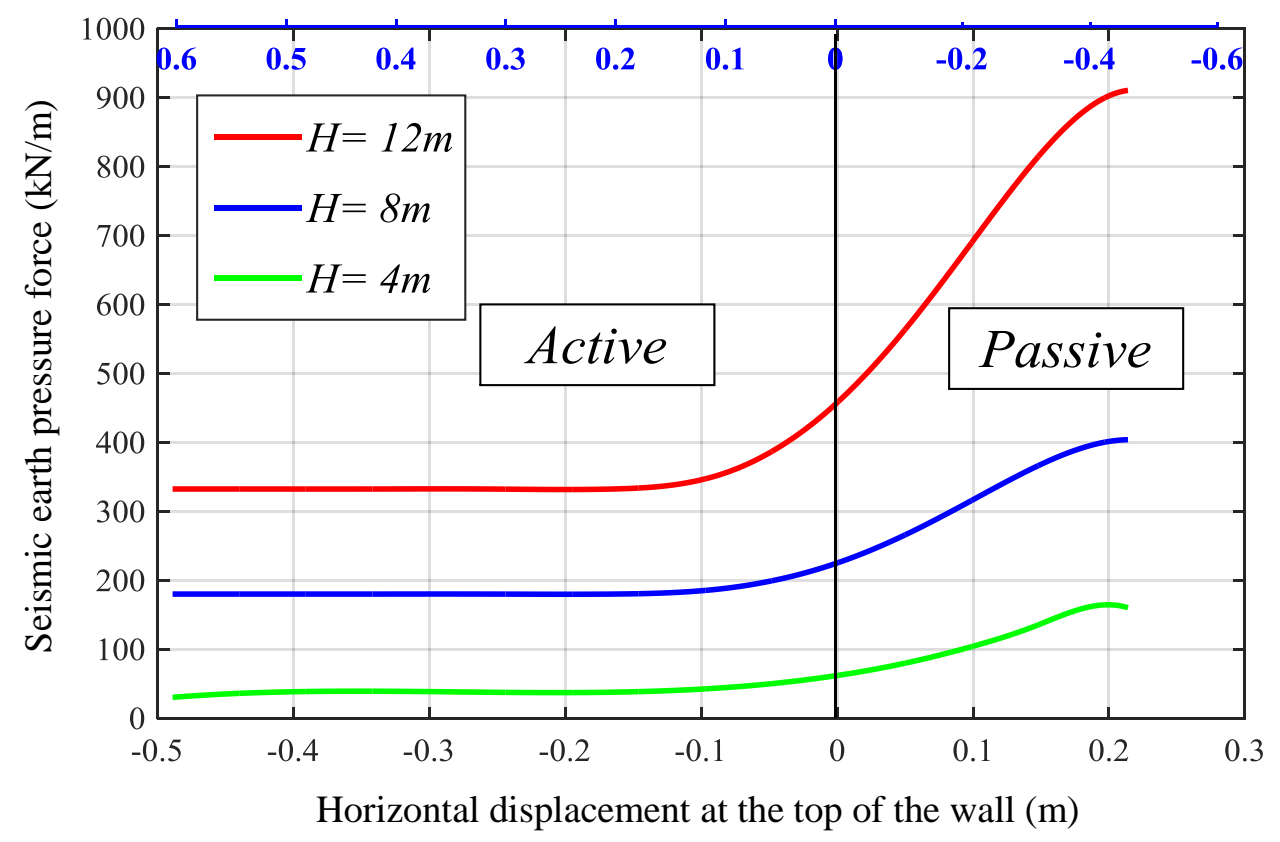

b

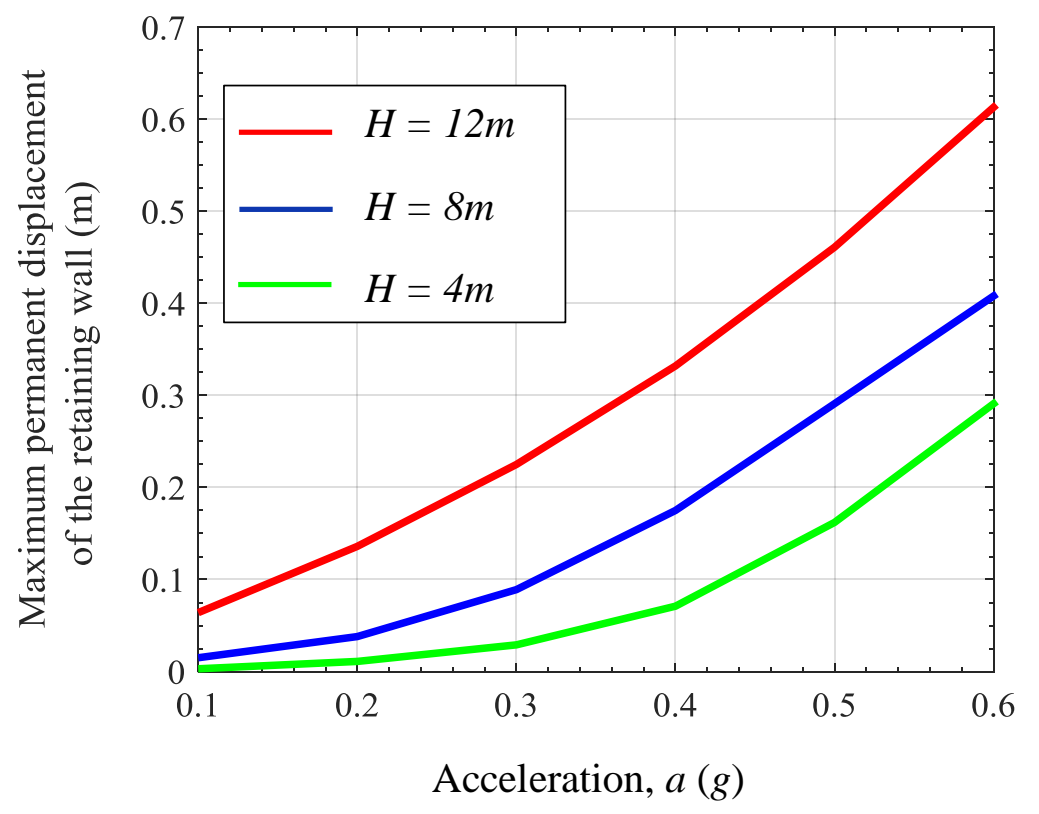

Fig. 21: Unique design chart for different retaining wall heights showing a relationship between: (a) seismic earth pressure force and horizontal displacement at the top of the retaining wall, (b) maximum permanent displacement of the retaining wall and amplitude of the seismic input motion. 



\section{$\mathbf{a}$}

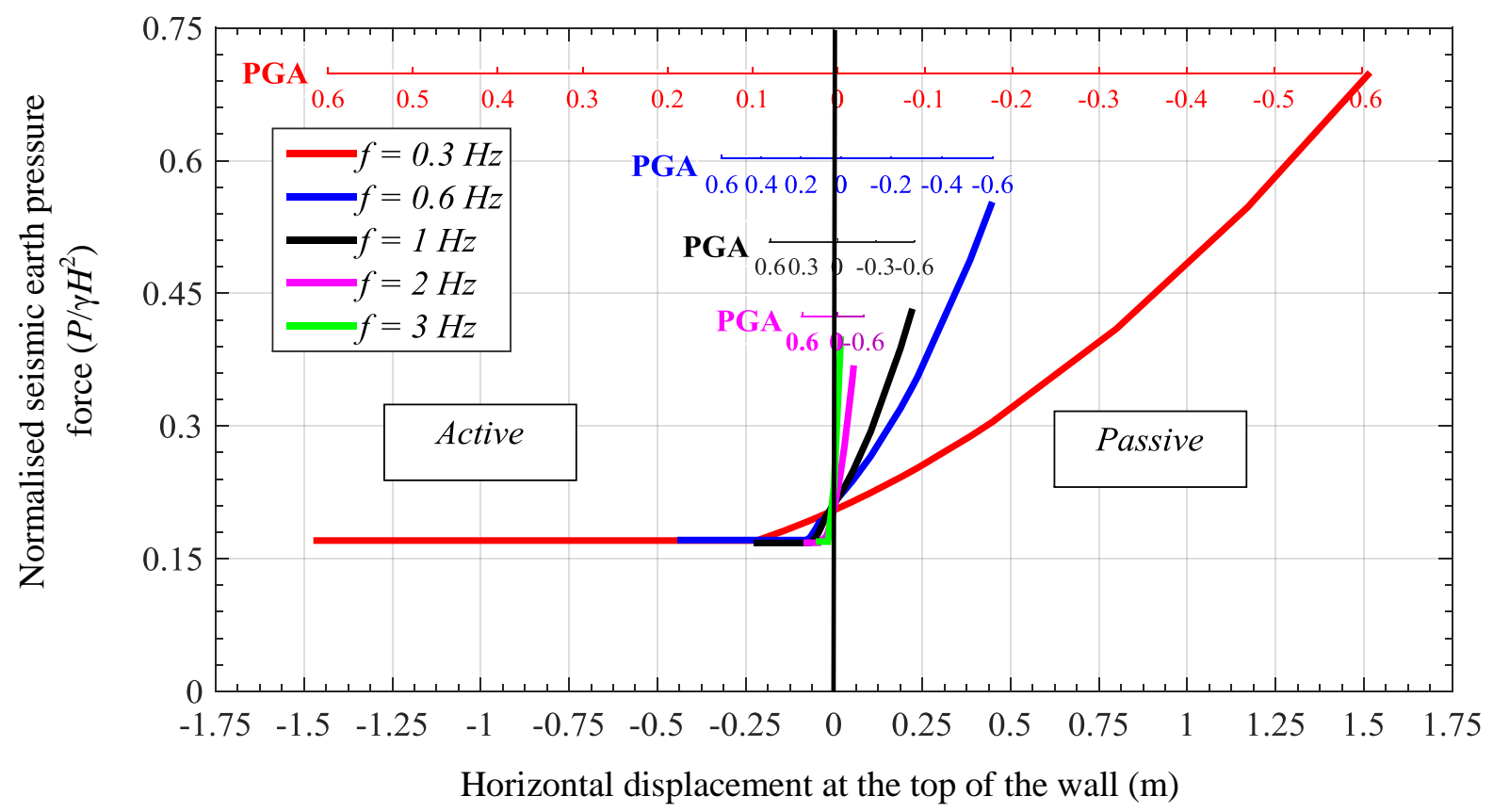

b

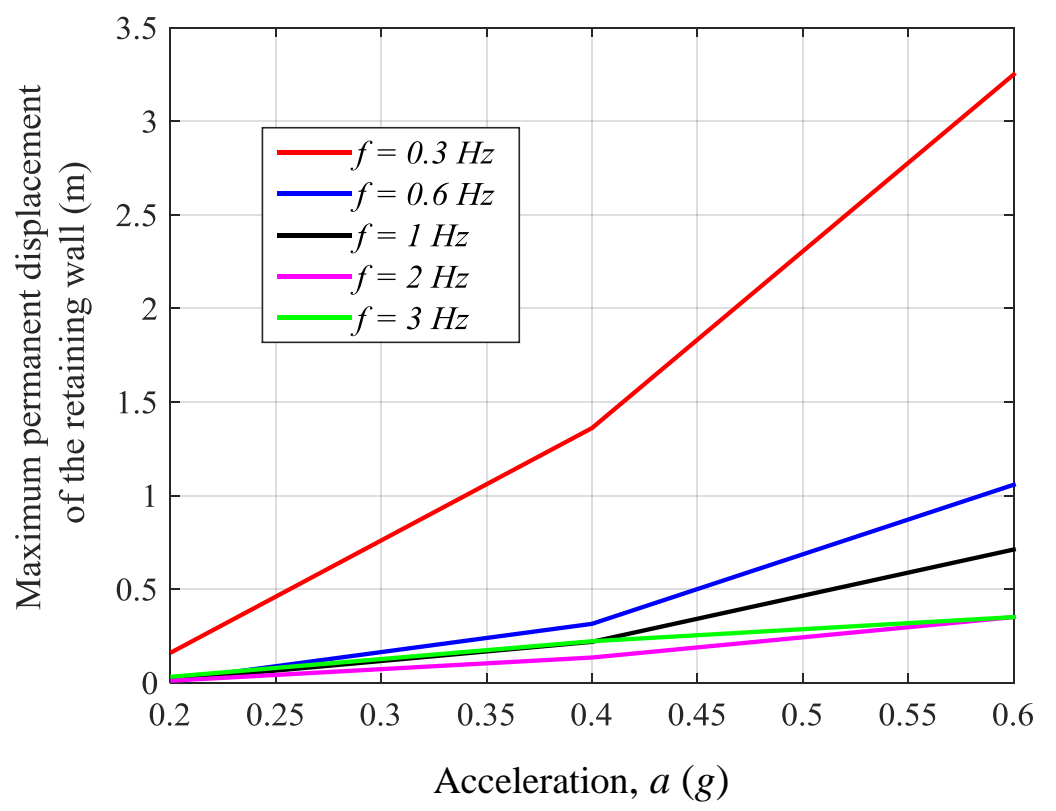

Fig. 22: Unique design chart for different frequency content and amplitude of seismic input motion showing a relationship between: (a) normalised seismic earth pressure force and horizontal displacement at the top of the retaining wall, (b) maximum permanent displacement of the retaining wall and amplitude of the seismic input motion. 


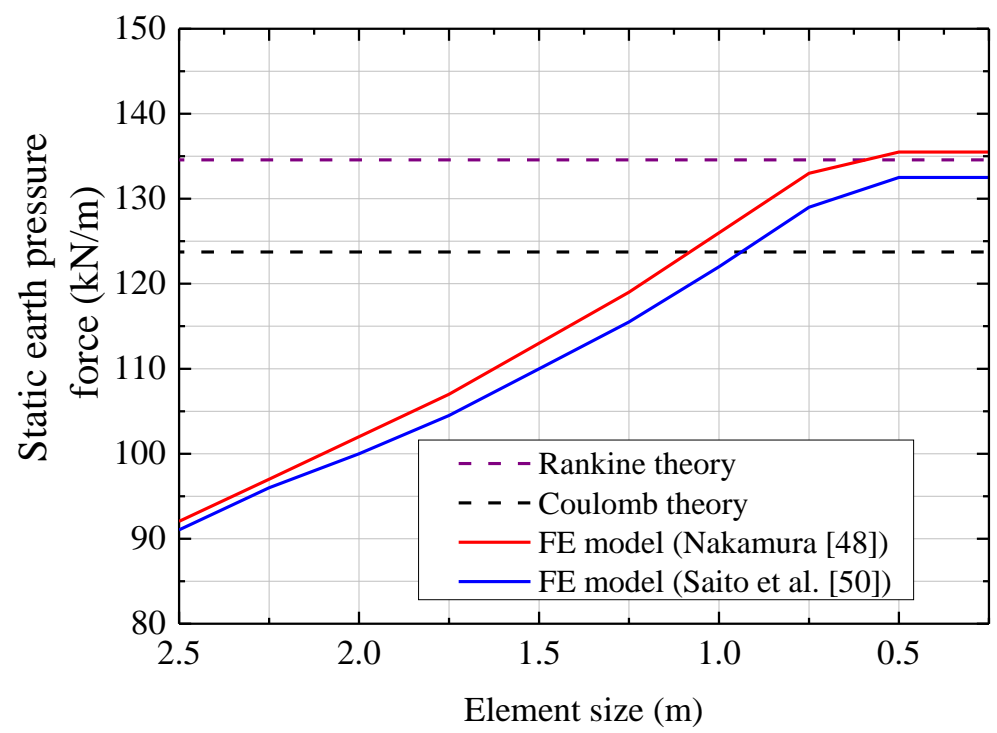

Fig. A.1: Convergence analysis results to decide the minimum size of the elements for the FE model. 